\title{
The reactivity of Cyclopropyl cyanide in Titan's atmosphere: a possible pre-biotic mechanism
}

\author{
E. Lopez ${ }^{\mathrm{a}}$, D. Ascenzi ${ }^{\mathrm{b}}$, P. Tosi ${ }^{\mathrm{b}}$, J.M. Bofill' , J. de Andrés ${ }^{\mathrm{a}}$, M. Albertía , J.M. Lucas ${ }^{\mathrm{a}}$, A. \\ Aguilar $^{\mathrm{a}^{*}}$ \\ a Departament de Ciència de Materials i Química Física, Institut de Química Teòrica i Computacional \\ (IQTCUB), Universitat de Barcelona, Martí i Franquès, 1, 08028 Barcelona, Spain \\ ${ }^{\mathrm{b}}$ Dipartimento di Fisica, Università degli Studi di Trento, I-38123 Trento, Italy \\ ${ }^{\mathrm{C}}$ Departament de Química Inorgànica i Química Orgànica, Institut de Química Teòrica i \\ Computacional (IQTCUB), Universitat de Barcelona, Martí i Franquès, 1, 08028 Barcelona, Spain \\ *Corresponding author:
}

\author{
Dept. Ciència de Materials i Química Física \\ Facultat de Química \\ Universitat de Barcelona \\ C/ Martí i Franquès, 1 \\ 08028-Barcelona \\ SPAIN \\ fax: +34934021231 \\ e-mail: a.aguilar@ub.edu
}

\begin{abstract}
Cyclopropyl cyanide and other simple nitriles detected on Titan's atmosphere could be precursors leading to the formation of organic macromolecules in the atmosphere of the largest Saturn's satellite. Proposing a thermodynamically possible mechanism that explains their formation and supports experimental results represents a difficult challenge. Experiments done in the Atomic and Molecular Physics Laboratory at the University of Trento (AMPL), have studied the ion-molecule reaction between cyclopropyl cyanide and its protonated form, reaction products being characterized by mass spectrometry. In addition to the expected ionmolecule adduct stabilized by non-covalent long-range interactions, in this work we prove that another distinct species having the same mass to charge ratio $(\mathrm{m} / \mathrm{z})$ of 135 is also produced. Moreover, from a previous study of the neutral cyclopropyl cyanide potential energy surface (PES) which shows a partial biradical character it has been possible to characterize the formation through the bimolecular reaction of a new covalent cyclic organic molecule. Calculations have been carried out at the ab initio Möller-Plesset (MP2) level of
\end{abstract}


theory, ensuring the connectivity of the stationary points by using the intrinsic reaction coordinate (IRC) procedure. In order to characterize the reaction transition state, multireference calculations were done using a complete active space involving six electrons and six molecular orbitals [CAS (6 e, 6 m.o.)]. This study opens the possibility of exploring the formation of new organic molecules by gaseous phase ion-molecule interaction schemes, such molecules having relevance in interstellar space and in astrobiology (and may be involved in the prebiotic molecular evolution).

\section{$\underline{\text { I . Introduction }}$}

Detailed analysis of emission-absorption spectra from stars, planets and interstellar medium (ISM), whether obtained from ground based astronomic centers or from launched space missions, has produced a huge amount of information on physical, chemical and geological properties of many sidereal bodies. Researching in chemical compositions has revealed the presence of a large variety of molecules, of both organic and inorganic nature, in some cases with identical or similar structures to those found on Earth. So far, almost 200 different molecular species have been detected in the ISM or circumstellar shells (for a complete list see The Cologne Database for Molecular Spectroscopy (CDMS) in http://www.astro.unikoeln.de/cdms/molecules), and a special attention has been reserved by exobiologists to the so called prebiotic species, i.e. molecules that are key intermediates for the synthesis of biologically relevant substances. For instance, species containing $\mathrm{C}-\mathrm{N}$ or $\mathrm{C} \equiv \mathrm{N}$ bonds such as amines and nitriles are considered to be precursors of aminoacids and nucleobases.

Nitriles have been detected also in the atmosphere of $\operatorname{Titan}^{1}$, the largest moon of Saturn, and one of the most studied celestial bodies today thanks to the recently completed CassiniHuygens mission ${ }^{2,3,4}$. Titan has attracted the interest of astrochemists and astrobiologists because of its dense and chemically rich atmosphere, that is believed to be similar to the primordial atmosphere of Earth ${ }^{5,6}$. Information on the composition of Titan's upper atmosphere and ionosphere have been obtained by the various instruments on board of the Cassini probe and Huygens lander ${ }^{2,3,7,8,9,10,11,12,13}$.

Besides $\mathrm{N}_{2}$ and $\mathrm{CH}_{4}$, the most abundant species, other higher mass components have been detected, thus making Titan's atmosphere one of the most complex in the solar system. Such a composite chemistry is originated by dissociation and ionization of the primary species due to UV photons and high energy particles, leading to highly reactive ions and radicals. It has been proposed that the nitrogen chemistry in Titan's upper atmosphere is initiated at high altitude by $\mathrm{N}$ atoms and ions reacting with $\mathrm{CH}_{4}$ and other hydrocarbons or radicals such as $\mathrm{CH}_{3}$ to form molecules with a C-N bond ${ }^{14,15,16,17}$ that can subsequently grow into larger species via reactions also involving ions ${ }^{11,18,19,20}$. 
The main motivation for this work has been the discovery of different small size nitrile compounds (such as $\mathrm{HCN}$, acetonitrile $\mathrm{CH}_{3} \mathrm{CN}$ or cyanoacetylene $\mathrm{HC}_{3} \mathrm{~N}$ ) in Titan's atmosphere ${ }^{21,22,23}$. These and other nitriles were found both in their protonated and neutral forms; in fact the high proton affinity of nitriles makes the proton transfer reaction from $\mathrm{HCNH}^{+}$or $\mathrm{C}_{2} \mathrm{H}_{5}{ }^{+}$an efficient process. In this paper we focus our attention on an ion detected by one of the mass spectrometer on board of Cassini at $\mathrm{m} / \mathrm{z} 68$ with a density of about 3-4 $\mathrm{cm}^{-3}$ and attributed to the molecular formula $\mathrm{C}_{4} \mathrm{H}_{5} \mathrm{NH}^{+11,24}$. This compound has been assigned as the protonated form of $\mathrm{C}_{4} \mathrm{H}_{5} \mathrm{~N}$ nitriles and the main formation mechanism, according to models in ref. 11 , is via the radiative association reaction between the $\mathrm{C}_{3} \mathrm{H}_{5}{ }^{+}$cation and hydrogen cyanide:

$$
\mathrm{C}_{3} \mathrm{H}_{5}^{+}+\mathrm{HCN} \rightarrow \mathrm{C}_{4} \mathrm{H}_{5} \mathrm{NH}^{+}+\text {hu }
$$

Alternatively, the reaction of $\mathrm{c}_{-} \mathrm{C}_{3} \mathrm{H}_{6}{ }^{+}$with $\mathrm{HCN}$ has been proposed to give an ion with molecular formula $\mathrm{H}_{6} \mathrm{C}_{4} \mathrm{~N}^{+}$:

$$
\text { C- } \mathrm{C}_{3} \mathrm{H}_{6}{ }^{+}+\mathrm{HCN} \rightarrow \mathrm{H}_{6} \mathrm{C}_{4} \mathrm{~N}^{+}+\mathrm{H}
$$

in addition to a smaller channel in which $\mathrm{CH}_{2} \mathrm{CNH}^{+} / \mathrm{CH}_{3} \mathrm{CN}^{+}$and $\mathrm{C}_{2} \mathrm{H}_{4}$ are formed ${ }^{25,26}$.

The $\mathrm{C}_{4} \mathrm{H}_{5} \mathrm{NH}^{+}$ion can be considered as the protonated form of the corresponding neutral species, however the assignment is complicated by the fact that there are several isomers for the nitrile molecular formula $\left(\mathrm{C}_{4} \mathrm{H}_{5} \mathrm{~N}\right)$, namely cis/trans but-2-enenitrile (or crotonitrile $\mathrm{CH}_{3} \mathrm{CHCHCN}$ ), but-3-enenitrile (or allylcyanide $\mathrm{H}_{2} \mathrm{CCHCH}_{2} \mathrm{CN}$ ), pyrrole $\left(\mathrm{c}^{-} \mathrm{C}_{4} \mathrm{H}_{4} \mathrm{NH}\right.$ ), methyl-2 propenenitrile (or methacrylonitrile $\mathrm{CH}_{3} \mathrm{C}(\mathrm{CN}) \mathrm{CH}_{2}$ ) and cyclopropanenitrile (or cyclopropyl cyanide c- $\left.\mathrm{C}_{3} \mathrm{H}_{5} \mathrm{CN}\right)^{27}$. A nitrile of molecular formula $\mathrm{C}_{4} \mathrm{H}_{5} \mathrm{~N}$, but unspecified structure is also detected in a laboratory simulation chamber aimed at reproducing Titan's atmospheric chemistry, and particularly the chemical reactivity leading to the formation of aerosols and tholins ${ }^{19}$.

Since the unexpected observation of heavy cations and anions in the upper atmosphere of Ti$\tan (\sim 1000 \text { kilometers })^{9,28,29}$ the idea has emerged that complex ion-neutral chemistry in Titan's upper atmosphere plays a major role in the formation of progressively more complex hydrocarbon and N-containing molecules, ultimately leading to tholins and aereosols that precipitate at lower latitudes, originating the observed haze surrounding the satellite's surface. Recently, some ion-molecule reactions that utilize abundant building blocks such as $\mathrm{C}_{2} \mathrm{H}_{2}, \mathrm{C}_{2} \mathrm{H}_{4}$ and $\mathrm{C}_{2} \mathrm{H}_{6}$ have been included in the chemical models of Titan's atmosphere with the aim of reproducing the observed mass spectra ${ }^{30}$.

In particular, reactions involving two medium sized pre-formed building blocks deserve a special attention because such type of processes have the advantage - over alternative mechanisms requiring sequential additions of small species - of attaining substantial growth 
in molecular size within a single reactive encounter. In a similar manner ion-molecule reactions could be invoked to explain the formation of heavy nitriles.

In the hope of adding some new information to the nitrile ionic chemistry that might be useful for improving existing models of Titan's atmospheric chemistry, we have generated the protonated species $\mathrm{C}_{4} \mathrm{H}_{5} \mathrm{NH}^{+}$from all the possible neutral isomers of molecular formula $\left(\mathrm{C}_{4} \mathrm{H}_{5} \mathrm{~N}\right)$ and we have investigated their reactivity with the corresponding neutrals.

Excluding pyrrole (due to its aromaticity) all protonated isomers were found to react with their neutral forms giving the corresponding ion-molecule adducts (at $\mathrm{m} / \mathrm{z} 135$ ) through the formation of a hydrogen bridge between the $\mathrm{N}$ atoms of the corresponding cyanide groups. In some cases, in addition to adduct formation, other reaction products with a lower $\mathrm{m} / \mathrm{z}$ ratio were also found.

In this work are reported experimental results as well as a computational study on the following reaction of protonated cyclopropyl cyanide with its corresponding neutral, in their electronic singlet ground state:

$$
\mathrm{C}_{4} \mathrm{H}_{5} \mathrm{~N}+\mathrm{C}_{4} \mathrm{H}_{5} \mathrm{NH}^{+} \rightarrow \mathrm{C}_{8} \mathrm{H}_{10} \mathrm{~N}_{2} \mathrm{H}^{+}
$$

The experimentally observed product $\mathrm{C}_{8} \mathrm{H}_{10} \mathrm{~N}_{2} \mathrm{H}^{+}$could be one of the possible different adducts produced by non-covalent ion-molecule interactions, although other isomeric species resulting from a further evolution could also be produced. Moreover, an exhaustive $a b$ initio electronic structure calculations on the PESs of the bimolecular reaction (0) and for separated reactants have been carried out. After the introduction, the paper is structured as follows: Section II reports on the experimental measurements with a short description of the experimental setup followed by experimental results found, while the most relevant chemical structures and topology features of the ab initio calculated PESs are shown in Section III. In section IV the experimental and computational results on reaction (0) are discussed and interpreted. Final conclusions are given in Section V.

\section{Experimental Measurements}

\section{A. Brief description of the experimental setup}

Experiments have been carried out using a Triple Quadrupole Mass Spectrometer (model API3000TM LC/MS/MS, ABSciex, USA) at the University of Trento, equipped with atmospheric pressure ion sources such as APCI (Atmospheric Pressure Chemical Ionisation) and ESI (ElectroSpray ionization), and previously used to study reactivity of cations and anions with stable neutrals ${ }^{31,32,33}$. A schematic diagram of the set-up is given in Figure 1 . In this system a quadrupole mass spectrometer (Q1) acts as a filter selecting from the source 
generated ions those are required for the experiment $\left(\mathrm{C}_{4} \mathrm{H}_{5} \mathrm{NH}^{+}\right.$ions at $\mathrm{m} / \mathrm{z} 68$ in the present case), which then enter into a non-mass-resolving radio frequency (RF-only) quadrupole (Q2) where the neutral target gas is previously injected (cyclopropyl cyanide $\mathrm{C}_{4} \mathrm{H}_{5} \mathrm{~N}$ in the present case) and which acts as a reaction chamber. The nominal collision energy of the reacting species can be selected by changing the energy with which the reactant ions enters in Q2. The pressure of neutral reactant admitted into the middle quadrupole can be estimated by measuring the pressure in the chamber containing Q2 and using a known calibration factor that takes into account the conductance of the scattering cell surrounding Q2. The resulting pressures for the experiments described here were in the range $4-6 \times 10^{-4}$ mbar. All ionic species produced in Q2 in reaction (0) or other processes then pass to quadrupole mass spectrometer Q3, where they are characterized according to their $m / z$ values.

The desired protonated cyclopropyl cyanide cations were generated using the APCI ${ }^{34,35}$ source fed by a cyclopropyl cyanide solution in methanol $\left(10^{-3}-10^{-4}\right.$ molar concentration) via a micrometric syringe pump, with constant flow rate of $10 \mu \mathrm{l} / \mathrm{min}$. High-purity $\mathrm{N}_{2}$, obtained by boil-off from a liquid nitrogen Dewar, was used both as nebulizer and as curtain gas. The temperature of the source region was kept at $250^{\circ} \mathrm{C}$ during all measurements. Typical experimental parameters optimized for the production of $\mathrm{C}_{4} \mathrm{H}_{5} \mathrm{NH}^{+}$ions were the following: Declustering potential $30 \mathrm{~V}$, nebulizer current applied to the corona discharge needle $3.0 \mu \mathrm{A}$, focusing potential $140 \mathrm{~V}$, and entrance potential $10 \mathrm{~V}$.

\section{B. Experimental Results}

The mass spectra measured at four different collision energies (CE) for the $\mathrm{C}_{4} \mathrm{H}_{5} \mathrm{~N}+\mathrm{C}_{4} \mathrm{H}_{5} \mathrm{NH}^{+}$ system are shown in Figure 2. Two major signals can be readily appreciated, the one at $\mathrm{m} / \mathrm{z}$ 68 , being clearly attributable to the protonated cyclopropyl cyanide reagent, and that at $\mathrm{m} / \mathrm{z}$ 135 to the $\mathrm{C}_{8} \mathrm{H}_{10} \mathrm{~N}_{2} \mathrm{H}^{+}$adduct. In addition, two minor signals are visible at $\mathrm{m} / \mathrm{z} 136$ and 69: the former is associated tothe ${ }^{13} \mathrm{C}$ isotopic contribution of the peak with $\mathrm{m} / \mathrm{z}=135$ (the intensity of peak at $m / z 136$ is about $4 \%$ with respect to peak at $m / z 135$, as expected from the natural abundance of one ${ }^{13} \mathrm{C}$ carbon in the $\mathrm{C}_{4} \mathrm{H}_{5} \mathrm{~N}$ neutral). Due to the high mass resolution in $\mathrm{Q} 1$, signal at $\mathrm{m} / \mathrm{z} 69$ can not be attributed to ${ }^{13} \mathrm{C}$ isotope contribution from the $\mathrm{C}_{4} \mathrm{H}_{5} \mathrm{NH}^{+}$ion generated in the source, but it is rather due to the self-protonation reaction $\mathrm{C}_{4} \mathrm{H}_{5} \mathrm{NH}^{+}+$ ${ }^{13} \mathrm{CC}_{3} \mathrm{H}_{5} \mathrm{~N} \rightarrow{ }^{13} \mathrm{CC}_{3} \mathrm{H}_{5} \mathrm{NH}^{+}+\mathrm{C}_{4} \mathrm{H}_{5} \mathrm{~N}$.

Taking into account that reaction (0) essentially describes the formation of any $\left[\mathrm{C}_{8} \mathrm{H}_{10} \mathrm{~N}_{2} \mathrm{H}\right]^{+}$ ionic compound, in order to emphasize the specific formation of an ion-molecule adduct without covalent interactions among reactants, hereafter, the formation of ion products involving non-covalent interactions will be labeled as reaction (0.1):

$$
\mathrm{C}_{4} \mathrm{H}_{5} \mathrm{~N}+\mathrm{C}_{4} \mathrm{H}_{5} \mathrm{NH}^{+} \rightarrow\left[\mathrm{C}_{8} \mathrm{H}_{10} \mathrm{~N}_{2} \mathrm{H}\right]^{+} \text {(adduct) }
$$




\section{Computational Study}

A full understanding of the experimental results and the system's reactivity requires a deep and detailed knowledge of the topology and main features of the PES on which the reactive process evolves. In our case, both neutral $\left(\mathrm{C}_{4} \mathrm{H}_{5} \mathrm{~N}\right)$ and protonated $\left(\mathrm{C}_{4} \mathrm{H}_{5} \mathrm{NH}^{+}\right)$reactants have a closed shell electronic configuration so that the reaction can be expected to proceed adiabatically on the ground singlet electronic state of the PES associated with the $\left(\mathrm{C}_{8} \mathrm{H}_{10} \mathrm{~N}_{2} \mathrm{H}\right)^{+}$ supermolecule. The main topological features of these PESs have been obtained by performing $a b$ initio calculations at the perturbation second order Möller-Plesset (MP2) ${ }^{36}$ level of theory using the electronic structure Gamess 2013 package ${ }^{37}$. The basis set used is the Poples' 6-31G(d,p) basis set, including $d$ polarization functions for each heavy atom and $p$ polarization functions for each hydrogen. The cyclopropyl molecule and its derivatives tend to suffer an opening of the three-carbon ring due to the high tension produced by their acute bond angles which moreover leads to a weak orbital overlap, producing a biradical species in its ground singlet state. To study this process, the unrestricted Hartree-Fock (UHF) methodology has been used to characterize the corresponding single molecule PES. Taking into account that the cyclopropyl cyanide biradical can also be involved in the bimolecular reaction with the protonated cyclopropyl cyanide on the same PES, in order to fully characterize the different structures associated with potential energy wells and transition states on the ground singlet PES, a complete active space (CASSCF) electronic structure calculation $^{38,39,40}$ was done, since this methodology is suitable for the treatment of systems with unpaired electrons and radical structures. By adequately choosing the active space this method is able to describe the ground state of the open shell structures with no preconceptions regarding the orientation of the unpaired electrons ${ }^{40,41}$. However, the main weakness of multiconfigurational procedures lies in the difficulty involved in treating the dynamic correlation. To solve this problem once the geometries of stationary points have been optimized at the CASSCF level, a multirreference single point calculation was carried out to include as much as possible the dynamic correlation correction. In order to choose correctly the active subspace orbitals to be included in the CASSCF treatment, Pulay's UHF natural orbitals (UHFNOS) procedure has been applied ${ }^{42,43}$ on the studied PES surface has been obtained and different stationary points have been characterized along the reaction pathway. Applying the IRC method ${ }^{41,44,45}$ the connectivity between the different stationary points along the MEP has been confirmed in all cases, finally describing a reaction path.

\section{A. $A b$ initio characterization of the singlet ground state of protonated and neutral cyclopropyl cyanide and adduct structures}

$A b$ initio calculations for reactant species, in their singlet electronic ground state, have been done carrying out a full optimization of their equilibrium geometries and a Hessian matrix 
analysis at the MP2 level. Optimized structures for both neutral and protonated cyclopropyl cyanide are shown in Figure 3, where some small differences between them can be appreciated. In particular, in the protonated species, the C3-C2 and C3-C1 bond distances are slightly longer (by $0.022 \AA$ ) while the C1-C2 one is a little bit shorter (by $0.022 \AA$ ) than the corresponding distances in neutral cyclopropyl cyanide. In addition, $\mathrm{C}-\mathrm{H}$ distances are slightly greater (around $0.001 \AA$ ) in the protonated molecule. Moreover, while C3-CN and $\mathrm{C} \equiv \mathrm{N}$ bond distances decrease by $0.030 \AA$ and $0.017 \AA$, respectively, in the protonated molecule, bond angles in both molecules do not change too much (see Figure 3 and Table 1). In both cases the $c$ angle (centered in C3), is the smallest one, while $a$ and $b$ angles are almost identical in both cases.

Ion-molecule reactions are normally controlled by long-range forces and produce stabilized adducts via non-covalent interactions via barrierless processes on the $\mathrm{PES}^{46}$. For reaction (0.1) it is to be expected that the most stable $\left[\mathrm{C}_{8} \mathrm{H}_{10} \mathrm{~N}_{2} \mathrm{H}\right]^{+}$geometry would be one in which both molecules are kept together by a proton bridge interaction between the $\mathrm{H}^{+}$of the protonated molecule and the non-bonding electron pair on the $\mathrm{N}$ atom in the neutral one. In this adduct, hereafter labeled as adduct (1), major positive charges are centered on the central $\mathrm{H}(0.498)$ and on the two -CN carbons (0.435 in each one). However, since charges on $\mathrm{N}$ atoms are around -0.458 in both cases, total charges on -CN groups remain practically null, so the adduct's total positive charge is essentially located on the central $\mathrm{H}(0.498)$ and on the two $\mathrm{H}$ atoms attached to the $\mathrm{C}$ atoms adjacent to $-\mathrm{CN}$ groups (0.224 each one). The optimized equilibrium structure for adduct (1) is shown in Figure 4, where the most relevant distances and angles are given, while other angles are shown in Table 2. The $\mathrm{C}_{4} \mathrm{H}_{5} \mathrm{~N}-\mathrm{C}_{4} \mathrm{H}_{5} \mathrm{NH}^{+}$ interaction leads to an adduct with an atomic sequence between interacting cyanide groups (C14-C12-N11-H13-N10-C8-C3) which shows a collinear arrangement, bond distances in both fragments being practically identical. Moreover, both 3-carbon rings show exactly the same angle values, these being intermediate between those found for neutral and protonated cyclopropyl cyanide. It is noteworthy that in the optimized geometry of adduct (1), the two rings are not in a perfectly antiperiplanar position as expected, but they show a folded sideways configuration (see Figure 4). Rotation of the 3-carbon rings around the cyanideproton-cyanide collinear arrangement reveals a very flat area on the PES with flattened conformer minima separated by very low potential energy barriers.

In addition to adduct (1), other stable structures can be produced due to interactions between the non-bonding electrons on the neutral fragment's $\mathrm{N}$ atom (having a high electronic density) and atomic centers on the protonated molecule (having lower electronic densities). A detailed exploration of other possible arrangements stabilized by long-range ion-dipole interactions (i.e. non-covalent) led to the different optimized geometries summarized in Figure 5, and are also present in the PES of the reactive system. Three ion-molecule complexes (labeled as (2), (3) and (4)) were found and characterized either by the interactions between the $\mathrm{C}_{4} \mathrm{H}_{5} \mathrm{~N}$ 
fragment's $\mathrm{N}$ atom non-bonding electron pairs and both the $\mathrm{CN}$ group carbon and the $\mathrm{H}$ atoms of the protonated fragment (adducts (2) and (3)) or only with $\mathrm{H}$ atoms in the three-carbons ring (adduct (4)), clearly showing the different spatial arrangement of the $\mathrm{C}_{4} \mathrm{H}_{5} \mathrm{~N}$ and $\mathrm{C}_{4} \mathrm{H}_{5} \mathrm{~N}^{+}$ fragments in adducts. All characterized adduct structures, from (1) to (4), are related to true potential energy wells on the system's PES. As shown in Table 3, adduct (1), the most stable one, has a potential energy depth roughly twice that of the others. Adduct formation is an exothermic and barrierless reaction, so it can be qualitatively interpreted in terms of the Giosmousis-Stevenson-Langevin capture model (LGS) ${ }^{47}$ that was previously employed in the study of some alkali-ion organic molecule adducts ${ }^{48}$. The presence of these stabilized $\left[\mathrm{C}_{8} \mathrm{H}_{10} \mathrm{~N}_{2} \mathrm{H}\right]^{+}$non-covalent adducts statistically leads to an increase in the ion-molecule capture probability of reaction (0.1), since all of them contribute to the experimental measured signal at $m / z 135$.

\section{B. $A b$ initio characterization of the ground state $\mathrm{PES}$ for $\left[\mathrm{C}_{4} \mathrm{H}_{5} \mathrm{~N}-\mathrm{C}_{4} \mathrm{H}_{5} \mathrm{NH}\right]^{+}$reactive system.}

As it is well known, three-carbon atoms rings are heavily stressed due to the bond angles associated to the $\mathrm{sp}^{3}$ hybridization of carbon atoms. The possibility of a C-ring opening being not negligible, a full exploration of the reaction PES should to take into account the following possible reactions:

$$
\begin{array}{ll}
\mathrm{C}_{4} \mathrm{H}_{5} \mathrm{~N} \text { (closed ring) } & \rightarrow \mathrm{C}_{4} \mathrm{H}_{5} \mathrm{~N} \text { (open ring) } \\
\mathrm{C}_{4} \mathrm{H}_{5} \mathrm{NH}^{+} \text {(closed ring) } & \rightarrow \mathrm{C}_{4} \mathrm{H}_{5} \mathrm{NH}^{+} \text {(open ring) }
\end{array}
$$

Before starting the study the of the $\left[\mathrm{C}_{8} \mathrm{H}_{10} \mathrm{~N}_{2} \mathrm{H}\right]^{+}$PES', reactions (A) and (B) have been studied at the UHF level taking into account the biradical character of their products. In the case of (A), by using the C1-C3 bond distance (see Figure 3) as a reaction coordinate a reaction path was found which led from $\mathrm{C}_{4} \mathrm{H}_{5} \mathrm{~N}$ to a stable 1,3 propyl cyanide biradical. As shown in Figure 6 the evolution of the potential energy along the reaction pathway for reaction (A) has a transition state (TS) between reactants and products' local minima whose connectivity has been ensured by the IRC method ${ }^{43}$. Figures I and II given in the supplementary information, show molecular structure geometries for both TS and the 1,3 propyl cyanide biradical respectively, as well as their most relevant bond and angle distances. Moreover, Table A (see supplementary information) shows that the C3-C2-C1 angle changes from $60.40^{\circ}$ in cyclopropyl cyanide to $105.76^{\circ}$ in 1,3 propyl cyanide biradical strongly reducing the carbon ring stress, and the $\mathrm{C} 1-\mathrm{C} 3$ distance increases from $1.513 \AA$ in the reactant to $2.068 \AA$ at the TS. From this TS to the optimized 1,3 propyl cyanide biradical structure, C3-C2-C1 angle and C1-C3 distance increase up to $105.76^{\circ}$ and $2.400 \AA$, respectively. Energy values given in Table B show that reaction (A) has a $1.134 \mathrm{eV}$ high zero point potential energy barrier and that it is endothermic by about $1 \mathrm{eV}$. 
In the case of reaction (B) however (see Figure 6), since the potential energy of the system augmented continuously on increasing the C3-C2-C1 angle value, it can be concluded that a stable open-ring structure does not exist. These results show that the $\mathrm{C}_{4} \mathrm{H}_{5} \mathrm{~N}$-proton interaction prevents the $\mathrm{C}_{4} \mathrm{H}_{5} \mathrm{NH}^{+}$ring from opening, so that no stable biradical can be formed by the protonated cyclopropyl cyanide.

Taking into account that the cleavage of the C1-C3 bond in $\mathrm{C}_{4} \mathrm{H}_{5} \mathrm{~N}$ can lead to biradical structures in both singlet or triplet electronic states (leading to so-called spin contamination species ${ }^{49}$ ), the evolution of the potential energy as a function of the reaction coordinate C1C2-C3 angle is also given in Figure 7. From this figure it can be appreciated that the optimized triplet geometry leads to a minimum on the PES at an $112.50^{\circ} \mathrm{C} 1-\mathrm{C} 2-\mathrm{C} 3$ angle. Increasing this angle the triplet state acquires less energy than the singlet one, giving a nonadiabatic intersection of both PESs, a common feature in many organic systems ${ }^{50}$. In Figure III and in the right side column of Table A (both shown at the supplementary information) are shown the bond distances, relevant angles and the dihedral angles, respectively, for the optimized triplet state. These results lead to infer that biradical structures in both singlet and triplet states can play an important role in the reactivity of the $\left[\mathrm{C}_{8} \mathrm{H}_{10} \mathrm{~N}_{2} \mathrm{H}\right]^{+}$system and in the characterization of the main features of its PES.

A qualitative interpretation on the behaviors of reactions (A) and (B) can be made in terms of the electronic occupation of natural orbitals (N.O.) in both $\mathrm{C}_{4} \mathrm{H}_{5} \mathrm{~N}$ and $\mathrm{C}_{4} \mathrm{H}_{5} \mathrm{NH}^{+}$. Table 4 gives the N.O.s' occupation numbers for these reactants in their open-ring singlet structures, freezing the $\mathrm{C} 1-\mathrm{C} 2-\mathrm{C} 3$ angle at $110^{\circ}$ and considering an explicit set of four m.o. (those numbered from 17 to 20), of which 18 is the highest fully occupied molecular orbital (HOMO) and 19 the lowest unoccupied one (LUMO), reactants being in their equilibrium configurations. From data shown in the table it can be readily appreciated that the C1-C3 bond cleavage for $\mathrm{C}_{4} \mathrm{H}_{5} \mathrm{~N}$ can be seen as nearly homolytic resulting in an open-shell biradical (with occupation numbers 1.2561 and 0.7439 for HOMO and LUMO, respectively) while in $\mathrm{C}_{4} \mathrm{H}_{5} \mathrm{NH}^{+}$the bond cleavage is heterolytic (HOMO and LUMO occupation numbers are 2.00 and 0.00 , respectively) showing a closed-shell configuration. For $\mathrm{C}_{4} \mathrm{H}_{5} \mathrm{~N}$ in Figure 8 are given orbital distributions for the partially occupied $18^{\text {th }}$ and $19^{\text {th }}$ N.O.s and shows that the corresponding electronic population in each orbital is shared among different parts of the molecule, while similar representations were not obtained for $\mathrm{C}_{4} \mathrm{H}_{5} \mathrm{NH}^{+}$, since the protonmolecule interaction destabilizes the LUMO orbital and consequently keeps the HOMO doubly occupied.

Although both reactants in (0) and (0.1) show closed shell configurations, it can be expected from the UHF study of reaction (A) that the partial biradical character of $\mathrm{C}_{4} \mathrm{H}_{5} \mathrm{~N}$ molecule can play a role in contributing to the formation of covalently bound ion-molecule adducts which cannot be explained in terms of simple long-range non-covalent interactions, but which take 
place adiabatically on the same PES. For instance, the interaction between the $-\mathrm{C} \equiv \mathrm{N}$ triple bond of the $\mathrm{C}_{4} \mathrm{H}_{5} \mathrm{NH}^{+}$molecule and the unpaired electrons of the $\mathrm{C}_{4} \mathrm{H}_{5} \mathrm{~N}$ neutral (showing a partial biradical behavior) becomes possible, being this reaction similar to a Diels-Alder interaction or to a 1,3-Dipolar Cycloaddition ${ }^{42,51}$. To consider this possibility for the $\mathrm{C}_{4} \mathrm{H}_{5} \mathrm{~N}$ fragment in ground electronic singlet state of the $\left[\mathrm{C}_{8} \mathrm{H}_{11} \mathrm{~N}_{2}\right]^{+}$supermolecule, $a b$ initio calculations of the reaction PES have been performed at the complete active space selfconsistent field (CASSCF) level, the active space involving 6 molecular orbitals and 6 electrons CAS (6 m.o.,6 e $)$. An exhaustive exploration of the PES leads to localize a transition state (TS1) structure that (on properly analyzing the eigenvector associated with the negative eigenvalue of the Hessian matrix) clearly reveals the interaction between the unpaired electrons of the biradical structure, resulting from the cleavage of the C1-C3 bond in the cyclopropyl cyanide fragment, and the $\mathrm{C} \equiv \mathrm{N}$ bond of the protonated cyclopropyl cyanide (see the optimized TS1 structure in Figure 9). It is noteworthy that the C1-C3 distance is $2.545 \AA$, greater than those for the equilibrium geometry in the singlet or triplet bi-radical structures (2.400 and $2.502 \AA$, respectively) shown in supplementary information (Figures II and III). Moreover, the C1-C2 distance has increased while the C2-C3 one has decreased respect to their equilibrium values. In addition, this interaction strongly distorts the C14-C12$\mathrm{N} 11$ angle (a) in the $\left[\mathrm{C}_{4} \mathrm{H}_{5} \mathrm{NH}\right]$ fragment from collinearity to $154.47^{\circ}$, while the $\mathrm{C} 1-\mathrm{C} 2-\mathrm{C} 3$ angle (b) increases to $115.63^{\circ}$ in the biradical side of the supermolecule.

From TS1 structure the IRC procedure following the direction of the eigenvector associated with the vibrational mode of the imaginary frequency, leads on one direction to a minimum having the same linear structure of adduct (1) (see Fig. 4). In the other direction it leads to another minimum associated with a new cyclic product showing a five-center ring due to the formation of two new covalent bonds involving $\mathrm{C}(12) \equiv \mathrm{N}(11), \mathrm{C} 1$ and $\mathrm{C} 3$ atoms, as in the case of a [2+2] pericyclic cycloaddition reaction ${ }^{52,53,54}$. The structure of the most stable conformer (P1) is shown in Figure 10, while internal and dihedral angles in P1 are given in Table 5. The C1 and C3 atoms in the TS1 structure (see Figure 9) are prone to interact with the N11 and C12 centers, leading to the formation of the covalent penta-atomic ring rearrangement shown in Figure 10, (internal and dihedral angles in for $\mathrm{P} 1$ are given in Table 5). The IRC information and the TS1 structure points out that reaction (0) behaves as an allowed pericyclic reaction, carrying out the cyclization via a single step involving no biradical intermediates. Cycloadditions of 1,3-dipoles may occur either by concerted or stepwise mechanisms ${ }^{52}$, in our case being similar to a concerted and asynchronous cycloaddition. In terms of dipole interactions and resonant structures, the reactive process can be interpreted ${ }^{51}$ as being essentially dominated by promoting the biradical character of the cyclopropyl cyanide in the C1-C3 bond (which results from the interactions rising up when properly oriented reactant molecules approach), behaving as a cycloaddition reaction. The molecular rearrangement taking place during the supermolecule evolution from M1 to the TS1 transition state are 
highlighted in Figure 11, where a snapshot sequence of structures interpreting the reaction pathway between both stationary points along the IRC are shown. By strongly distorting the initially collinear $-\mathrm{C} \equiv \mathrm{N}-\mathrm{H}^{+}-\quad-\mathrm{N} \equiv \mathrm{C}$ - arrangement in $\mathrm{M} 1$ structure (snapshot $\mathrm{I}$ ) and simultaneously increasing the proton $-\mathrm{C} \equiv \mathrm{N}$ group distance of the $\mathrm{C}_{4} \mathrm{H}_{5} \mathrm{NH}$, a structure is reached (snapshot III) in which the three-center ring in the non-protonated cyclopropyl cyanide is conserved. From this nuclear configuration the system quickly evolves into a structure (snapshot IV) with the cleaved C1-C3 bond similar to that shown in Figure II (supplementary information). From this structure, following the ICR, the system rearranges by reorienting the two molecular fragments into the most favorable geometry for the formation of TS1 structure (snapshot VIII). Such rearrangement facilitates the interaction between $\mathrm{C} 1$ and $\mathrm{C} 3$ centers on the open structure of the un-protonated molecule with the $\mathrm{N} \equiv \mathrm{C}$ bond on the protonated cyclopropyl cyanide as shown in Figure 9.

Calculations show that long-range interactions between reactants lead to M1 intermediate that, through a transition state TS1, evolves into the P1 adduct, involving the formation of covalent bonds between reactants via the following reaction sequence

$$
\mathrm{C}_{4} \mathrm{H}_{5} \mathrm{~N}+\mathrm{C}_{4} \mathrm{H}_{5} \mathrm{NH}^{+} \rightarrow \mathrm{M} 1 \rightarrow \mathrm{TS} 1 \rightarrow \mathrm{P} 1
$$

thus completing the description of the reaction between the neutral and protonated cyclopropyl cyanide molecules with respect to the simpler ion-molecule adduct formation (0.1). The potential energy profile in terms of the Zero Point Energy (ZPE) along the reaction pathway leading to P1 via reaction (1) is given in Figure 12, where the different stationary points along the reaction pathway and their IRC connectivity on the adiabatic reactive PES is shown. Calculated electronic energies, ZPEs and total energies are given in Table 6, where total and ZPE energies for adduct (1), TS1 and P1 optimized structures are given together with total energies referred to reactants. Moreover, taking into account that CASSCF calculations only include electrostatic correlations, on the full geometry optimized TS1 structure a single point multi-reference interaction configuration (MRCI) calculation was done in order to include the dynamical correlation at this point along the energy reaction path. From values reported in Table 6 it can be inferred that the formation of the covalently bound product $\mathrm{P} 1$ is a $2.227 \mathrm{eV}$ exothermic process, but it shows a $1.877 \mathrm{eV}$ zero point energy barrier. On the other hand, $\mathrm{M} 1$ is stabilized by $1.485 \mathrm{eV}$ respect to reactants due to essentially non-covalent interactions between $\mathrm{C}_{4} \mathrm{H}_{5} \mathrm{~N}$ and $\mathrm{C}_{4} \mathrm{H}_{5} \mathrm{NH}^{+}$reactants.

\section{Discussion}

$A b$ initio quantum chemistry calculations on the ground singlet state of the $\left[\mathrm{C}_{8} \mathrm{H}_{11} \mathrm{~N}_{2}\right]^{+}$ supermolecule involving neutral cyclopropyl cyanide molecule $\left(\mathrm{C}_{4} \mathrm{H}_{5} \mathrm{~N}\right)$ and its protonated form $\left(\mathrm{C}_{4} \mathrm{H}_{5} \mathrm{NH}^{+}\right)$characterize (at least qualitatively) the experimental signal measured at $\mathrm{m} / \mathrm{z}$ 
135. In $\mathrm{C}_{4} \mathrm{H}_{5} \mathrm{NH}^{+}+\mathrm{C}_{4} \mathrm{H}_{5} \mathrm{~N}$ collisions, formation of an ion-molecule adduct can be expected. This can be essentially produced by long-range non-covalent ion-molecule interactions, including both permanent and induced dipoles. It can be expected too, that the ion-molecule adduct formation (with strong electrostatic interaction between proton center in $\mathrm{C}_{4} \mathrm{H}_{5} \mathrm{NH}^{+}$and the electronic density surrounding the $\mathrm{N}$ in the non-protonated $\left.\mathrm{C}_{4} \mathrm{H}_{5} \mathrm{~N}\right)$ via reaction $(0.1)$ will play a major role. Moreover, under these conditions and taking into account that the reaction leading to M1 (see Figure 12) is barrierless, a collinear configuration of the $-\mathrm{CN}-\mathrm{H}^{+}$and NCatomic centers can be expected, so as to reduce the repulsive interactions between terminal cyclopropyl groups found from calculations (Figure 4). However, other ion-molecule adducts' structures were found also (Figure 5) although not as stable as the proton bridge adduct (see Table 3), due to weaker electrostatic interactions. Thus, our calculations point to the existence of different non-covalent ion-molecule adducts contributing to the measured signal at $\mathrm{m} / \mathrm{q}$ 135, with contribution from adduct (1) being probably the largest one.

Cyclopropane and derivatives show high reactivity and undergo a wide a variety of ringopening reactions ${ }^{55,56}$. Attempting to follow a possible evolution of adduct (1) and taking into account the high reactivity of the two terminal cyclopropyl rings, a broad exploration of the PES was done, considering the possible biradical character of the cyclopropyl ring. The study was done at the CASSCF level being able to describe the full singlet electronic wave function of the system including contributions from open-shell singlet configurations. Results shown the reaction behaves as a pericyclic cycloaddition reaction ${ }^{52,53,54,57}$. From the experimental mass spectra shown in Figure 2, the ratio of signal intensities at $\mathrm{m} / \mathrm{z} 135$ (product adduct ion) and $m / z 68$ (parent ion signal) can be obtained at different nominal laboratory collision energies (CE) corresponding to 1.0, 2.0, 4.0 and $6.0 \mathrm{eV}$. For those CEs, the 135/68 signals ratios are $0.55,0.35,0.30$ and 0.20 , respectively. In light of our quantum chemistry calculations, and depending on collision energy value, signal at $\mathrm{m} / \mathrm{z} 135$ can be attributed to the different [(1) to (4)] non-covalent ion-molecule adducts as well as to the ring-shaped cation involving new covalent bonds. Taking into account that reactions forming adducts from (1) to (4) are barrierless processes, their formation could be rationalized in terms of the LGS capture model, particularly, for the most stable M1 (1) structure (see Figure 12).

According to the LGS model, at low nominal CEs (i.e. 1 and $2 \mathrm{eV}$ in Figure 2) measured signals should result only from formation of adducts (1) to (4), while intensities measured at higher CEs (4 and $6 \mathrm{eV}$ in Figure 2) could correspond to a mix of both (1) to (4) and ringshaped adducts. In fact, taking into account that the center of mass (CM) available energy is about 0.5 times the CE and that the ZPE potential energy barrier height is $1.877 \mathrm{eV}$, product ions at $\mathrm{m} / \mathrm{z} 135$ can indeed include a contribution from the ring-shaped covalent adduct. In fact, at 4 and $6 \mathrm{eV}$ nominal $\mathrm{CE}$ the ion-molecule collision complex can successfully overcome the barrier separating adduct (1) and T1 structures. In previous studies on reactive ionmolecule processes involving non-covalent adducts ${ }^{58,59}$, it was found that their formation was 
relevant only at low energies. Hence, for nominal CEs higher than the potential energy barrier associated to P1 structure formation, non-covalent adduct contribution ought to be regarded as negligible, so that only P1 is expected to contribute to the measured signal at $\mathrm{m} / \mathrm{z} 135$. Moreover, at each nominal CE the yield of adducts depends on their lifetimes which in turn also depend on decaying radiative processes, on the frequency of secondary collisions, on the total energy content and on the total angular moment of the system. On increasing the total energy, adducts can be backward decomposed to reactants, resulting in a decrease of the measured reactivity when the energy increases. Unfortunately, there is no way that the different contributions to measured intensities at $\mathrm{m} / \mathrm{z} 135$ can be identified.

As mentioned in the introduction, neutral and protonated cyclopropyl cyanide molecules are present in Titan's atmosphere, so it is not excluded that they can participate in its complex atmospheric chemistry and even in prebiotic chemistry. To elucidate the role played by $\mathrm{C}_{4} \mathrm{H}_{5} \mathrm{~N}$ and $\mathrm{C}_{4} \mathrm{H}_{5} \mathrm{NH}^{+}$in such processes, in addition to the present work, more experimental and computational studies will be required on the interaction of these complex nitriles and nitrile cations with other components of Titan's atmosphere, as well as on the fate of their reaction products. For instance, the P1 adduct, with its particular penta-carbon cycle structure, presents some ring strain and functional groups (cyclopropyl and cyanide) of recognized high reactivity, pointing out to a potentially relevant role in Titan's atmosphere chemistry. Considering Titan's albedo and its distance to the Sun a $82 \mathrm{~K}$ mean surface temperature is to be expected yet, if we take into account possible greenhouse effect ${ }^{60}$, absorption of solar radiation by dust particles ${ }^{61}$ and the presence of $\mathrm{CH}_{4}$ and $\mathrm{H}_{2}$ in the atmosphere, the real surface temperature could be as high as $150 \mathrm{~K}^{62,63}$, and some recent measurements point out a surface temperature of $200 \mathrm{~K}$ on Titan atmosphere ${ }^{64,65,66}$. Assuming that $\mathrm{C}_{4} \mathrm{H}_{5} \mathrm{~N}$ and $\mathrm{C}_{4} \mathrm{H}_{5} \mathrm{NH}^{+}$are in thermal equilibrium in Titan's atmosphere, the potential energy barrier associated to P1 formation of the structure would require an equilibrium temperature around $392 \mathrm{~K}$ in order to provide an average total energy content (from contributions of the translational, rotational and vibrational degrees of freedom of the reactants) which is far from the assessed $120-170 \mathrm{~K}$ temperature range in the upper atmosphere of $\operatorname{Titan}^{56}$. In this temperature range chemical structure calculations roughly allow to estimate thermal rate constant $k$ values for the isomerization reaction (1) ( $k \sim 3 \times 10^{-65} \mathrm{~s}^{-1}$ at $120 \mathrm{~K}$ and $k \sim 2 \times 10^{-42} \mathrm{~s}^{-1}$ at $\left.170 \mathrm{~K}\right)$ showing a low efficiency essentially due to the high potential energy barrier. An increase of the efficiency of reaction (1) can be possible by taking into account a contribution in terms of the tunnel effect through the TS1 potential energy barrier separating M1 and P1 structures. An estimation of the tunnel effect for the TS1 (with a $477.05 i \mathrm{~cm}^{-1}$ imaginary frequency) potential energy barrier assuming the Wigner conditions ${ }^{67}$ are satisfied, leads to a reactivity increase around of $136 \%$ and $68 \%$ at $120 \mathrm{~K}$ and $170 \mathrm{~K}$, respectively. However, even considering the significant contribution of the tunnel effect in the considered reaction its effect on the rate constant is not important and consequently reaction (1) is very inefficient in forming products P1 under 
Titan's atmosphere conditions. The low efficiency for reaction (1) forming the P1 product does not exclude the formation of this highly reactive specie that would to open the way for a wide set of chemical reactions of possible prebiotic interest in Saturn's satellite.

\section{Conclusions}

The ion-molecule reaction between neutral and protonated cyclopropyl cyanide (both present in Titan's atmosphere) has been studied using a tandem mass spectrometer apparatus, the formation of a singly charged ion at $\mathrm{m} / \mathrm{z} 135$ having been measured in gas phase. This compound can be associated to the formation of different non-covalent adducts. Among these, the most stable one has the two cyclopropyl cyanide molecules held together by a proton bridge bond connecting both -CN groups. For this most stable adduct conformation, MP2 $a b$ initio calculations have found a collinear geometry arrangement of cyanide groups on both sides of the proton. CASSCF calculations on the ground singlet PES of the reactive system along the reaction path has characterized a potential energy barrier associated with a first order transition state involving a biradical-like electronic structure of the non-protonated cyclopropyl cyanide interacting with the cyanide group of the protonated partner. This clearly shows the important role played in its formation by the singlet open shell electronic structure allowed in the CASSCF electronic wave function. From the top of this potential energy barrier the reaction proceeds to a potential energy minimum associated with the formation of a reaction product showing a penta-atomic ring structure that requires the formation of new covalent bonds between the original reactants.

Our study shows that formation of non-covalent adducts via association reaction is the dominant reaction channel for protonated nitriles reacting with other nitriles at low collision energies. Under our experimental conditions of temperatures and pressures, that are quite different from those of Titan, the stabilization of the so formed complexes is attained by secondary collisions. Although the probability of stabilization by subsequent collisions is unlikely at the low pressures of the upper atmosphere of Titan (about $10^{-7}$ mbar at the peak of the ionosphere), the radiative lifetime of the complex could compete with its lifetime of dissociation back into the reactant species and thus reaction might proceed by emission of a photon. The probability of radiative association is well known to increase when the size of the molecular species increases and the temperature decreases. Hence, it is reasonable to assume that radiative association reactions among heavy species are an important channel and it may be deemed responsible for molecular growth. Reaction product P1 (appearing at the same $\mathrm{m} / \mathrm{z}$ value as the previously mentioned hydrogen bridged adduct, and therefore, indistinguishable from it), has a completely different chemical structure and it is expected to be very reactive. This fact opens the possibility of very interesting new and unknown chemical processes in planetary atmospheres and prebiotic chemistry. 


\section{ACKNOWLEDGEMENTS}

The authors acknowledge financial support from the Spanish Ministerio de Economia y Competividad (MINECO Projects CTQ2013-41307-P and CTQ2016- 76423-P) and from the University of Trento. Thanks are also due the Generalitat de Catalunya-AGAUR (Projects 2014 SGR 25 and 2014 SGR0139) and to the Consorci de Serveis Universitaris de Catalunya (CSUC) and the Fundació Catalana per a la Recerca for allocating supercomputing time.

\section{REFERENCES}

1 S.M. Horst, Journal of Geophysical Research-Planets, 2017, 122, 432-482.

2 http://www.esa.int/Our_Activities/Space_Science/Cassini-Huygens/The_mission

3 https://saturn.jpl.nasa.gov/ \& https://saturn.jpl.nasa.gov/science/titan/

4 Book “Titan from Cassini-Huygens”, Editors: Brown, Robert, Lebreton, Jean Pierre, Waite, Jack, Publisher: Springer, 2010

5 F. Raulin, C. McKay, J. Lunine, T. Owen “Titan's astrobiology” in Chapter 9 of the Springer 2010 book cited in [4]

6 V. Vuitton, O. Dutuit, M. A. Smith and N. Balucani, "Chemistry of Titan's atmosphere” in "Titan: Interior, Surface, Atmosphere, and Space Environment" (ISBN: 9780521199926), Editors: I. Müller-Wodarg, C. A. Griffith, E. Lellouch, T. E. Cravens Eds., Publisher: Cambridge University Press, Series: Cambridge Planetary Science (No. 14). Chapter 7, 2014

7 Bézard, B.; Yelle, R.V. and Nixon, C.A. “The composition of Titan's atmosphere” in "Titan: Interior, Surface, Atmosphere, and Space Environment” (ISBN: 9780521199926), Editors: I. Müller-Wodarg, C. A. Griffith, E. Lellouch, T. E. Cravens Eds., Publisher: Cambridge University Press, Series: Cambridge Planetary Science (No. 14). Chapter 5, 2014

8 J.H. Waite Jr et al. Science, 2005, 308, 982-986.

9 J. H. Waite Jr., D. T. Young, T. E. Cravens, A. J. Coates, F. J. Crary, B. Magee, J. Westlake, Science, 2007, 316, 870-875.

10 T. E. Cravens, I. P. Robertson, J. H. Waite, R. V. Yelle, et al, Geophysical Research Letters, 2006, 33, L07105.

11 V. Vuitton, R. V. Yelle, and M. J. McEwan, Icarus, 2007, 191, 2, 722-742.

12 B. A. Magee, J. H. Waite, K. E. Mandt, J. Westlake, J. Bell and D. A. Gell, Planet. Space Sci., 2009, 57(14-15), 1895-1916.

13 J. Cui, R. V. Yelle, V. Vuitton, J. H. Waite Jr, et al, Icarus, 2009, 200, 2, 581-615.

14 S. K. Atreya, E. Y. Adams, H. B. Niemann, J. E. Demick-Montelara, T. C. Owen, M. Fulchignoni, F. Ferri, E. H. Wilson, Planetary and Space Science, 2006, 54, 12, 1177-1187. 
15 N. Balucani, F. Leonori, R. Petrucci, E. Segoloni, P. Casavecchia, 2009, "Laboratory studies on the reactions of formation of nitriles and oxygenated compounds of relevance to the atmosphere of Titan”, Memorie della Soc. Astron. Ital Supplementi, 2007, 11, 147-154

16 N. Balucani, F. Leonori, R. Petrucci, M. Stazi, D. Skouteris, M. Rosi, P. Casavecchia, Faraday Discuss., 2010, 147, 189-216.

17 O. Dutuit, N. Carrasco, R. Thissen, V. Vuitton, C. Alcaraz, P. Pernot, N. Balucani, P. Casavecchia, A. Canosa, S. Le Picard, J.C. Loison, Z. Herman, J. Zabka, D. Ascenzi, P. Tosi, P. Franceschi, S. D. Price, P. Lavvas, "Critical review of $\mathrm{N}, \mathrm{N}^{+}, \mathrm{N}^{+}{ }_{2}, \mathrm{~N}^{++}$, and $\mathrm{N}^{++}{ }_{2}$ main production processes and reactions of relevance to Titan's atmosphere", The Astrophysical Journal Supplement Series, 2013, 204, 20-64.

18 V. Vuitton, R. V. Yelle, V. G. Anicich, The Astrophysical Journal, 2006, 647, 175-178.

19 T. Gautier, N. Carrasco, A. Buch, C. Szopa, E. Sciamma-O’Brien, G. Cernogora, Icarus, 2011, 213, 625-635.

20 A. Ali, E.C. Sittler Jr., D. Chornay, B.R. Rowe, C. Puzzarini, Planetary and Space Science, 2015, 109, 46-63.

21 S. Vinatier, B. Bézard, T. Fouchet, N. A. Teanby, et al., Icarus, 2007, 188, 1, 120-138.

22 N. A. Teanby, P. G. J. Irwin, R. de Kok, C. A. Nixon, et al. Icarus, 2006, 181, 1, 243-255.

23 M.S. Richard, T.E. Cravens, C. Wylie, D. Webb, Q. Chediak, R. Perryman, K.E. Mandt, J. Westlake, J.H. Waite, I.P. Robertson, B.A. Magee, N.J.T. Edberg, Journal of Geophisical Research: Space Physics, 2014, 120, 1264-1280.

24 V. Vuitton, R. V. Yelle and P. Lavvas, (Rewiew), Philosophical Transactions of the Royal Society A. Mathematical, Physical and Engineering Sciences, 2009, 367, 729-741.

25 M. J. McEwan, G. B. I. Scott, V. Anicich, Int. J. Mass Spectrom. Ion Proc., 1998, 172, 209-219.

26 V. Anicich, M. J. McEwan, Planetary and Space Science, 1997, 45, 897-921.

27 G. J. Molina-Cuberos, K. Schwingenschuh, J. J. Lopez-Moreno, R. Rodrigo, L. M. Lara, V. Anicich, Journal of Geophysical Research, 2002, 107, E11, 5099.

28 K. Ågren, N. J. T. Edberg, J-E. Wahlund, Geophys. Res. Lett., 2012, 39, L10201

29 A. Wellbrock, A. J. Coates, G. H. Jones, G. R. Lewis, J. H. Waite, Geophysical Researc Letters, 2013, 40, 4481-4485.

30 J. H. Westlake, J. H. Waite Jr., N. Carrasco, M. Richard, T. Cravens, Journal of Geophisical Research: Space Physics, 2014, 119, 5951-5963.

31 F. Lindén, C. Alcaraz, D. Ascenzi, J.-C. Guillemin, L. Koch, A. Lopes, M. Polášek, C. Romanzin, J. Žabka, I. Zymak, W. D. Geppert, J. Phys. Chem. A, 2016, 120, 5337-5347.

32 J. Aysina, A. Maranzana, G. Tonachini, P. Tosi, D. Ascenzi, J. Chem. Phys., 2013, 138, 204310. 
33 A. Giordana, G. Ghigo, G. Tonachini, D. Ascenzi, P. Tosi, G. Guella, J. Chem. Phys., 2009, 131, 024304.

34 E. C. Horning, D. I. Carroll, I. Dzidic, K. D. Haegele, M. G. Horning and R. N. Stillwell, Journal of Chromatography A, 1974, 99, 13-21.

35 J. R. Chapman, "Practical organic mass spectrometry: a guide for chemical and biochemical analysis”. John Wiley \& Sons Ltd., 1995, Second Edition.

36 C. M. Aikens, S. P. Webb, R. L. Bell, G. D. Fletcher, M. W. Schmidt and M. S. Gordon, Theor. Chem. Acc., 2003, 110, 233.

37 M. W. Schmidt, K. K. Baldridge, J. A. Boatz, S. T. Elfert, M. S. Gordon, J. H. Jensen, S. Koseki, N. Matsunaga, K. A. Nguyen, S. J. Su, T. L. Windus, M. Dupuis, J. A. Montgomery. GAMESS Version: 1. May 2013 (R1). Iowa State University. Journal of Computational Chemistry, 1993, 14, 1347-1363.

38 M. W. Schmidt and M. S. Gordon, Annu. Rev. Phys. Chem., 1998, 49, $233-66$.

39 N. Koga and K. J. Morokuma, Am. Chem. Soc., 1991, 113, 1907-1911.

40 R. D. Bach, J. L. Andres, A. L. Owensby, H. B. Schlegel and J. J. McDouall, J. Am. Chem. Soc., 1992, 114, 18, 7207-7217.

41 M. S. Gordon, M. W. Schmidt, C. E. Dykstra, G. Frenking, K. S. Kim and G. E. Scuseria, "Theory and Applications of Computational Chemistry: The first Forty Years". Elsevier, 2005, p. 1167. Chem. Soc, 1992, 114, 7207-7217.

42 P. Pulay, T. P. Hamilton, J. Chem. Phys., 1988, 88, 4926-4933.

43 J. M. Bofill, P. Pulay, J. Chem. Phys., 1989, 90, 3637-3746.

44 K. Fukui, J. Phys. Chem., 1970, 74, 4161.

45 C. Gonzalez and H. B. Schlegel, J. Chem. Phys., 1989, 90, 2154.

46 E. López, J. M. Lucas, J. de Andrés, M. Albertí, J. M. Bofill, D. Bassi and A. Aguilar, J. Chem. Phys., 2014, 141, 164310.

47 R. D. Levine, “Molecular reaction dynamics”. Cambridge University Press, 2005.

48 J. Aguilar, J, M. Lucas, J. de Andrés, M. Albertí, D. Bassi, A. Aguilar, J. Chem. Phys. 2013, 138, 184310.

49 P. K. Nandi, T. Kar and A. B. Sannigrahi, Journal of Molecular Structure (Theochem). 1996, 362, 69-75.

50 L. J. Butler, Annual review of physical chemistry, 1998, 49(1), 125-171.

51 R. Huisgen, Angewante, 1963, 2, 11, 633-645.

52 K. N. Houk, J. González, and Y. Li, Acc. Chem. Res., 1995, 28, 81-90.

53 I. Fleming, "Pericyclic reactions”. Oxford Chemistry Primers. Oxford University Press, 
USA. 2015. Second Edition.

54 J.J. Vollmer and K. L. Servis, Journal of Chemical Education, 1970, 47(7), 491.

55 C. A. Carson and M. A. Kerr, Chemical Society Reviews, 2009, 38(11), 3051-3060.

56 H. N. Wong, M. Y. Hon, C. W. Tse, Y. C. Yip, J. Tanko and T. Hudlicky, Chem. Rev., 1989, 89(1), 165-198.

57 R. B. Woodward and R. Hoffmann, Journal of the American Chemical Society, 1965, 87:2, 395.

58 E. López, J. M. Lucas, J. de Andrés, M. Albertí, J. M. Bofill, D. Bassi and A. Aguilar, Phys. Chem. Chem. Phys., 2011, 13, 15977-15984.

59 E. López, J. M. Lucas, J. de Andrés, M. Albertí, J. M. Bofill, A. Aguilar, J. Phys. Chem. A., 2016, 120 (27), 4758-4769.

60 C. P. McKay, R. D. Lorenz and J. I. Lunine, Icarus, 1999, 137(1), 56-61.

61 D. M. Hunten, (Ed.). "The atmosphere of Titan: the proceedings of a workshop held at Ames Research Center, July 25 through 27, 1973”. (Vol. 340). National Aeronautics and Space Administration. 1974 .Washington, D.C.

62 S. K. Atreya, T. M. Donahue and W. R. Kuhn, Science, 1978, 201(4356), 611-613.

63 R. E. Danielson, J. J. Caldwell and D. R. Larach, Icarus, 1973, 20(4), 437-443.

64 D.M. Hunten. (Personal comunication). Arizona University. Dept. of Planetary Sciences and Lunar and Planetary Lab. Tucson, AZ, United States. 1978. “The Saturn System”; p 127140.

65 “Titan Saturn System Mission Study 2008: Final Report”. Task Order \#NMO710851. Final Report on the NASA contribution to a joint mission with ESA. 2009.

66 E. K. Conklin, B. L. Ulich and J. R. Dickel, Bulletin of the American Astronomical Society, 1977, 9, 471.

67 R.P. Bell. “The Tunnel Effect in Chemistry”. Chapman and Hall. London and New York, 1980. 
Figure caption

Figure 1: Schematic diagram of the QqQ experimental setup showing the quadrupole mass tandem spectrometer configuration. Q1: reactant ion mass selector; Q3: ion products mass analyzer; Q2: reaction cell quadrupole (guiding radio frequency only)

Figure 2: Experimental mass spectra showing the measured signal intensity (left hand side axis) as a function of the $\mathrm{m} / \mathrm{z}$ ratio (see the text) at different collision energies: (a) $1.0 \mathrm{eV}$; (b) $2.0 \mathrm{eV}$; (c) $4.0 \mathrm{eV}$; (d) $6.0 \mathrm{eV}$.

Figure 3: MP2 calculated equilibrium geometries at singlet ground state molecular structures for neutral (a) and protonated (b) cyclopropyl cyanide. On the left: side view; on the right: front view.

Figure 4: MP2 optimized equilibrium geometry for M1. The top view shows the collinear arrangement of the $-\mathrm{CN}-\mathrm{H}^{+}-\mathrm{CN}$ - centers. Below, a view of the same adduct according to different orientations.

Figure 5: MP2 optimized geometry structures of the ion-molecule adduct for Adduct (2), (3) and (4) stabilized by long-range ion-dipole interactions, discontinuous lines showing interacting centers for clarity.

Figure 6: Potential Energy profile for the cleavage of the C1-C3 bond using C3-C2-C1 angle as the reaction coordinate for both $\mathrm{C}_{4} \mathrm{H}_{5} \mathrm{~N}$ and $\mathrm{C}_{4} \mathrm{H}_{5} \mathrm{~N}^{+}$species. $\mathrm{C}_{4} \mathrm{H}_{5} \mathrm{~N}$ : ( $\square$ ); $\mathrm{C}_{4} \mathrm{H}_{5} \mathrm{~N}^{+}(\diamond)$

Figure 7: MP2 potential energy profile for the cleavage of the C1-C3 bond using C1-C2-C3 angle as the reaction coordinate for $\mathrm{C}_{4} \mathrm{H}_{5} \mathrm{~N}$ in the ground singlet ( $)$ state and in the first triplet $(\diamond)$ state.

Figure 8: Natural Orbitals, number 18 (HOMO) and 19 (LUMO), of open neutral biradical cyclopropyl cyanide (a), and open protonated cyclopropyl cyanide (b), where we can observe the different delocalization of the electrons in both structures.

Figure 9: MP2 optimized structure of the TS1 transition state: front (top) and plan (bottom) views are shown. Distances are given in angstroms, angles in degrees.

Figure 10: MP2 optimized structure of the P1 reaction product showing the five-centers 
covalent ring: An plan (top) and a side (bottom) views are shown. Distances are given in angstroms, angles in degrees.

Figure 11: Snapshot sequence of structures interpreting the reaction pathway between both stationary points M1 and P1 along the IRC leading to formation of the ring-shaped adduct (see text).

Figure 12: MP2 adiabatic potential energy profile showing the different stationary point (and structures) along the reaction pathway for the $\mathrm{C}_{4} \mathrm{H}_{5} \mathrm{~N}+\mathrm{C}_{4} \mathrm{H}_{5} \mathrm{NH}^{+}$reactive process leading to the P1 covalent structure adduct on the ground singlet state of the system. 


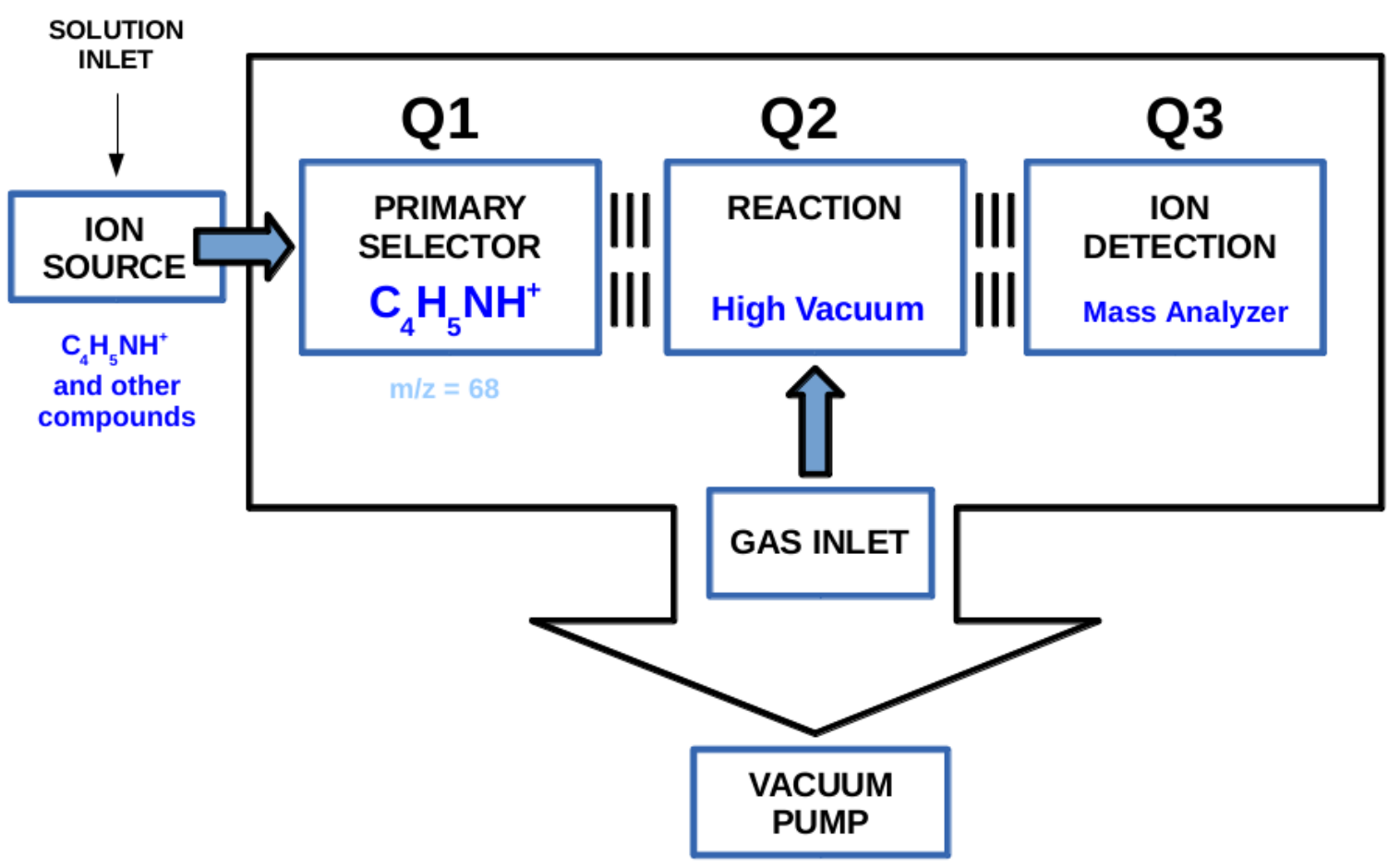

Figure 1 


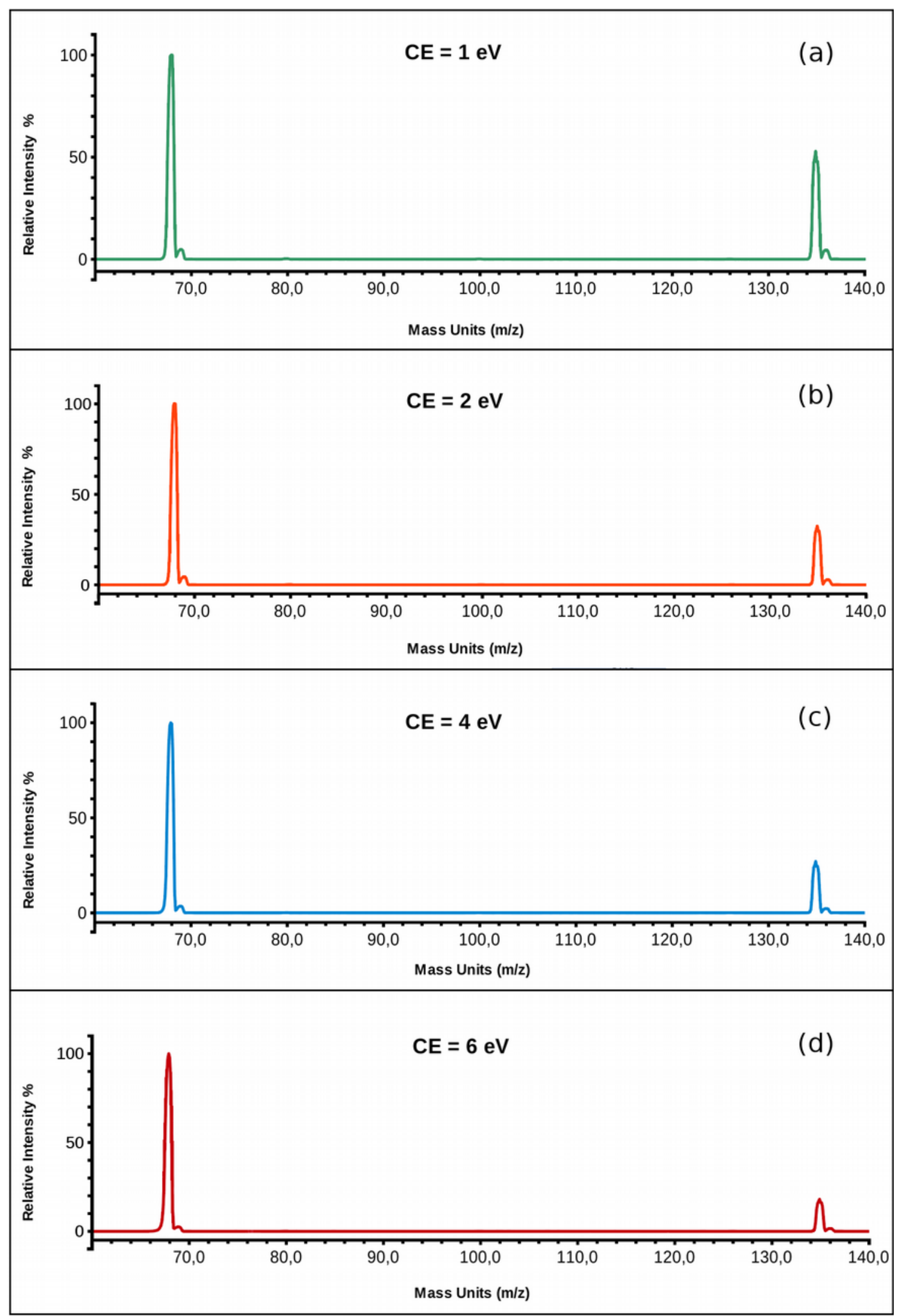


Figure 2 

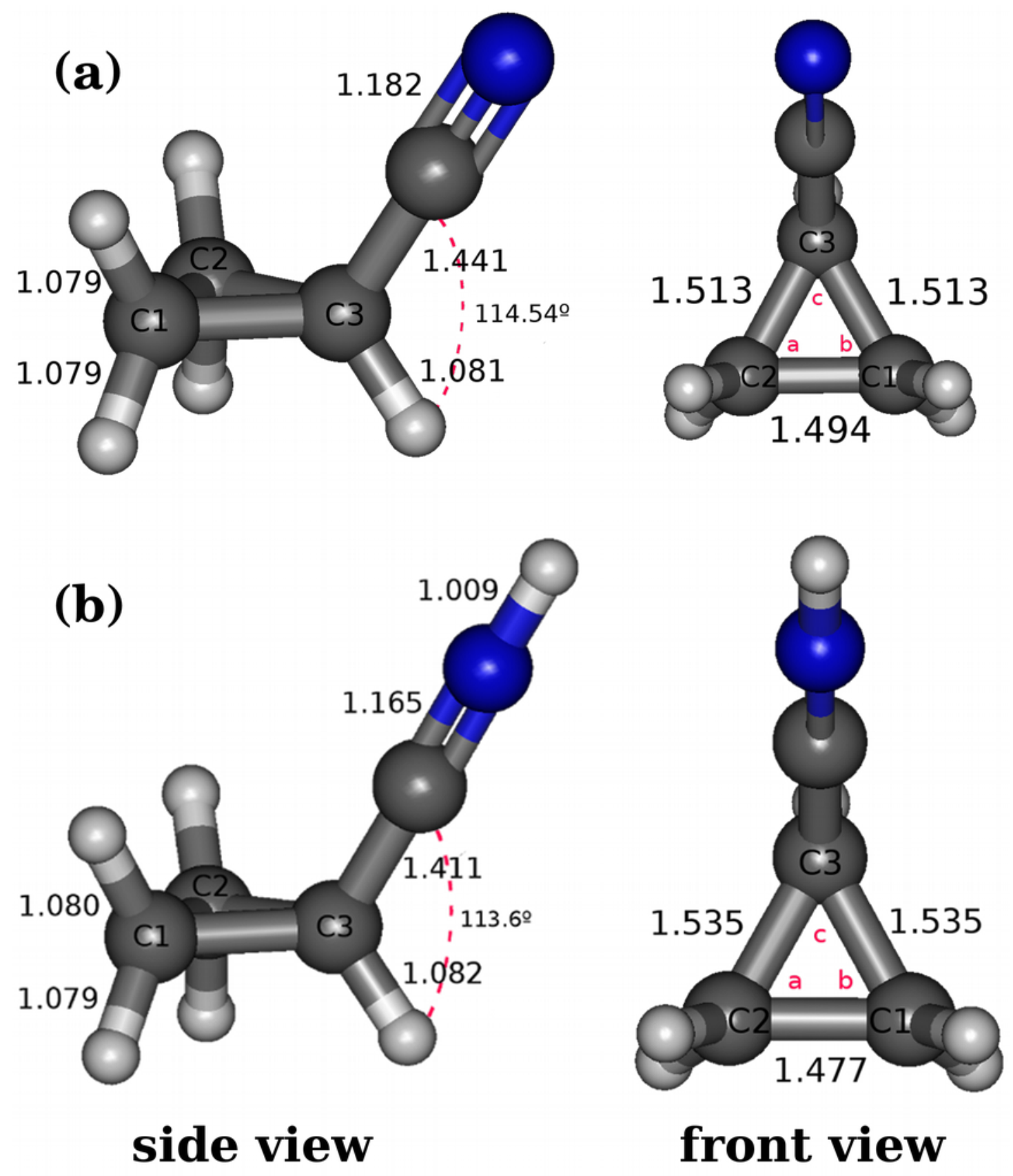

Figure 3 

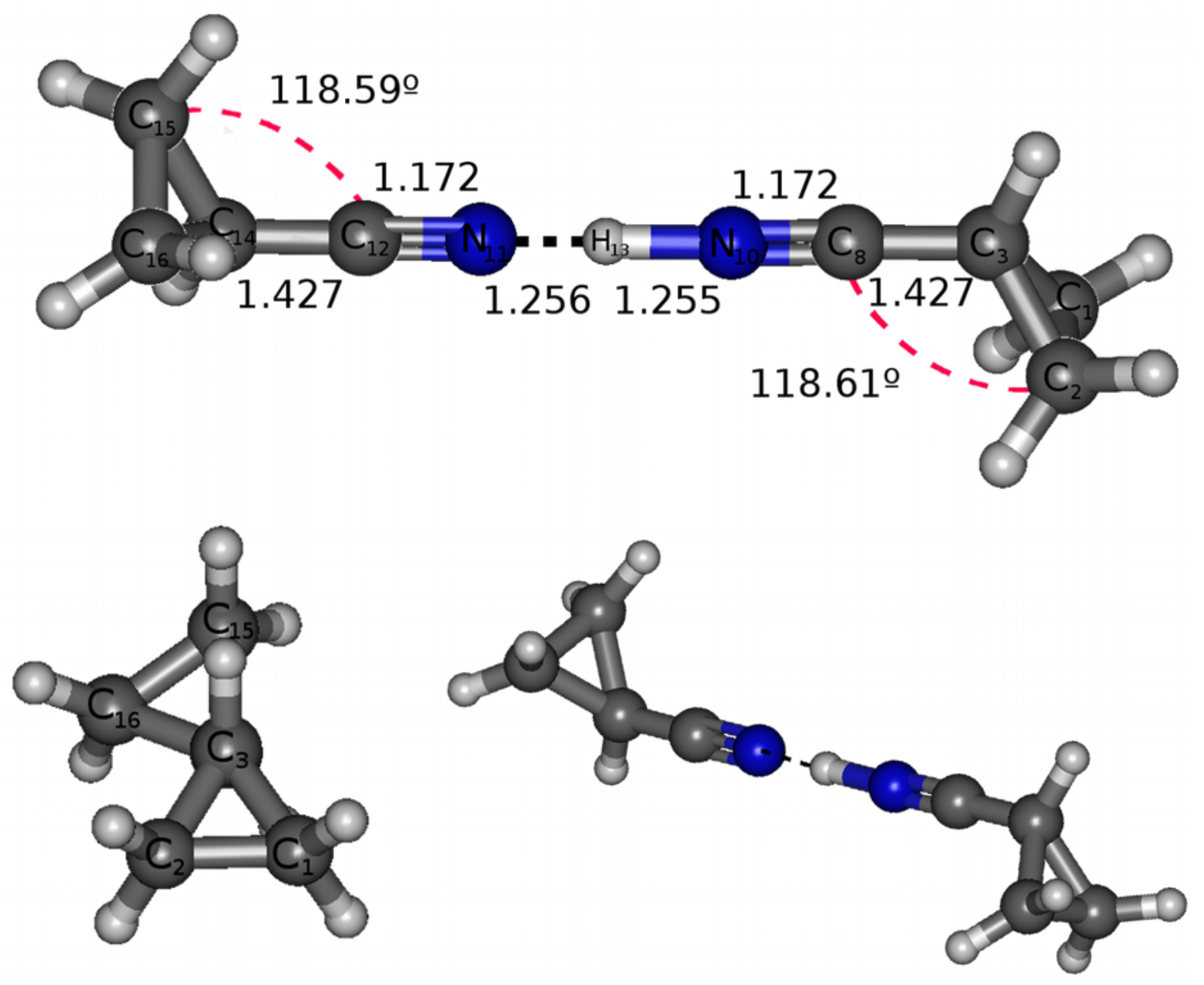

Adduct(1)

Figure 4 


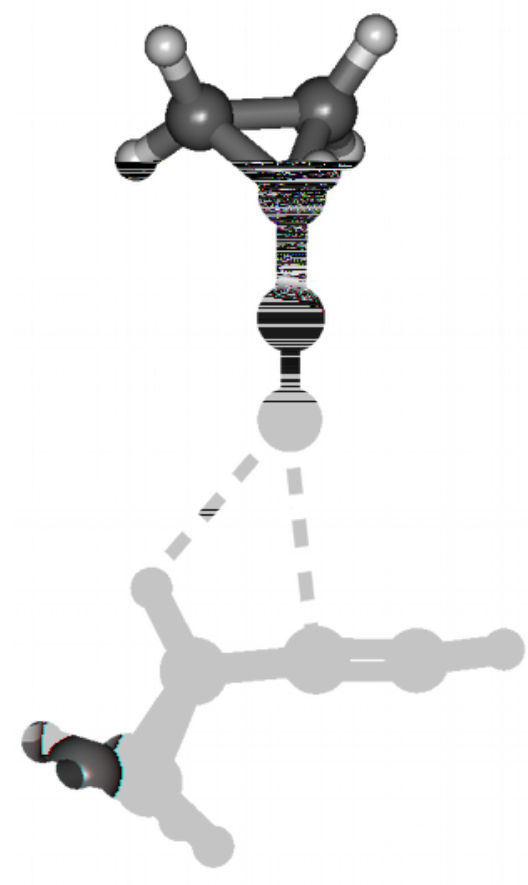

Adduct(2)

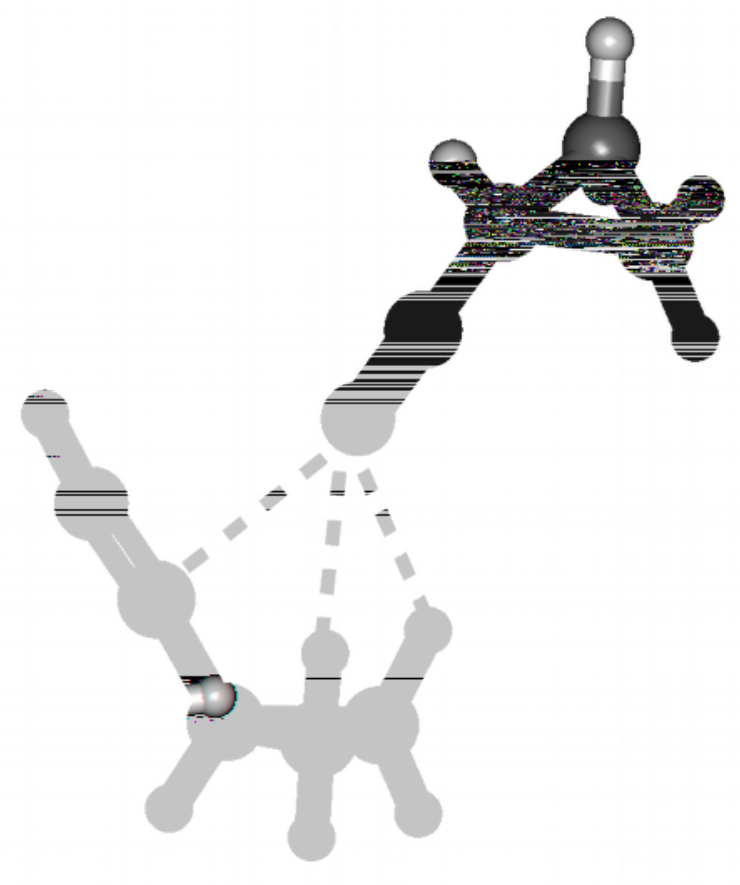

Adduct(3)

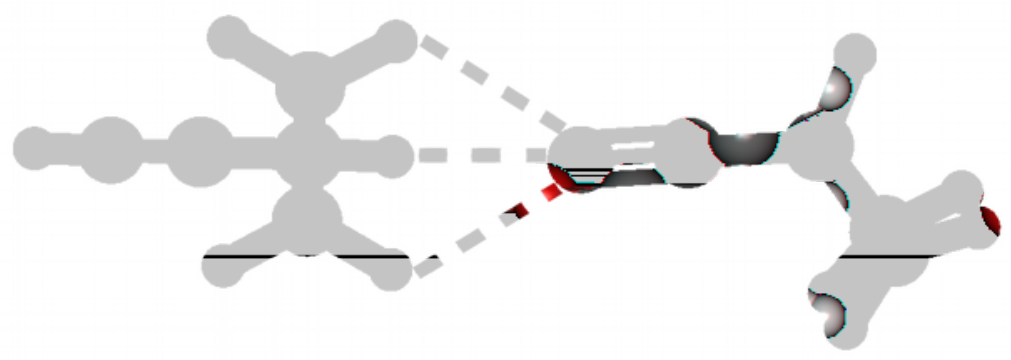

Adduct(4)

Figure 5 


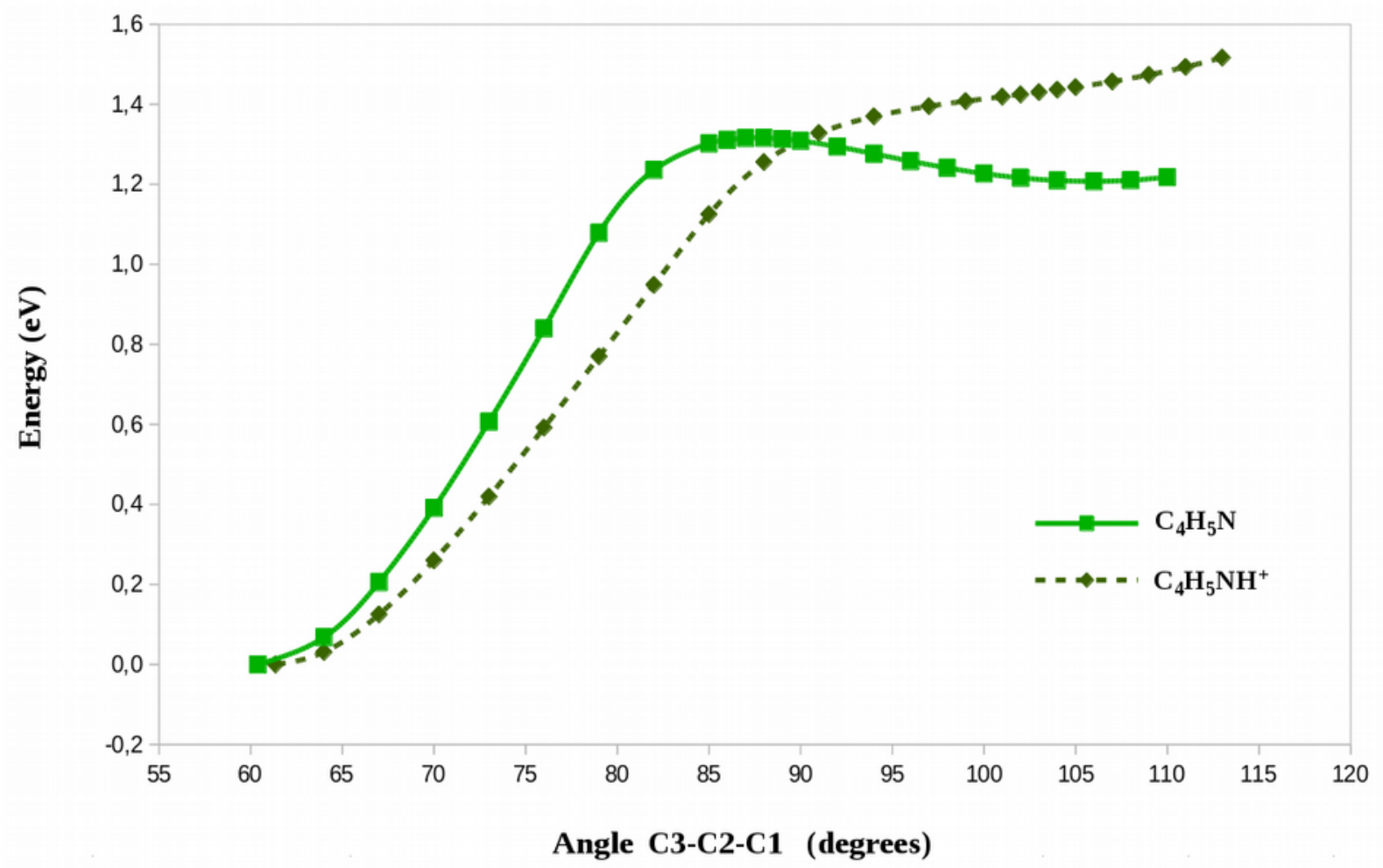

Figure 6 


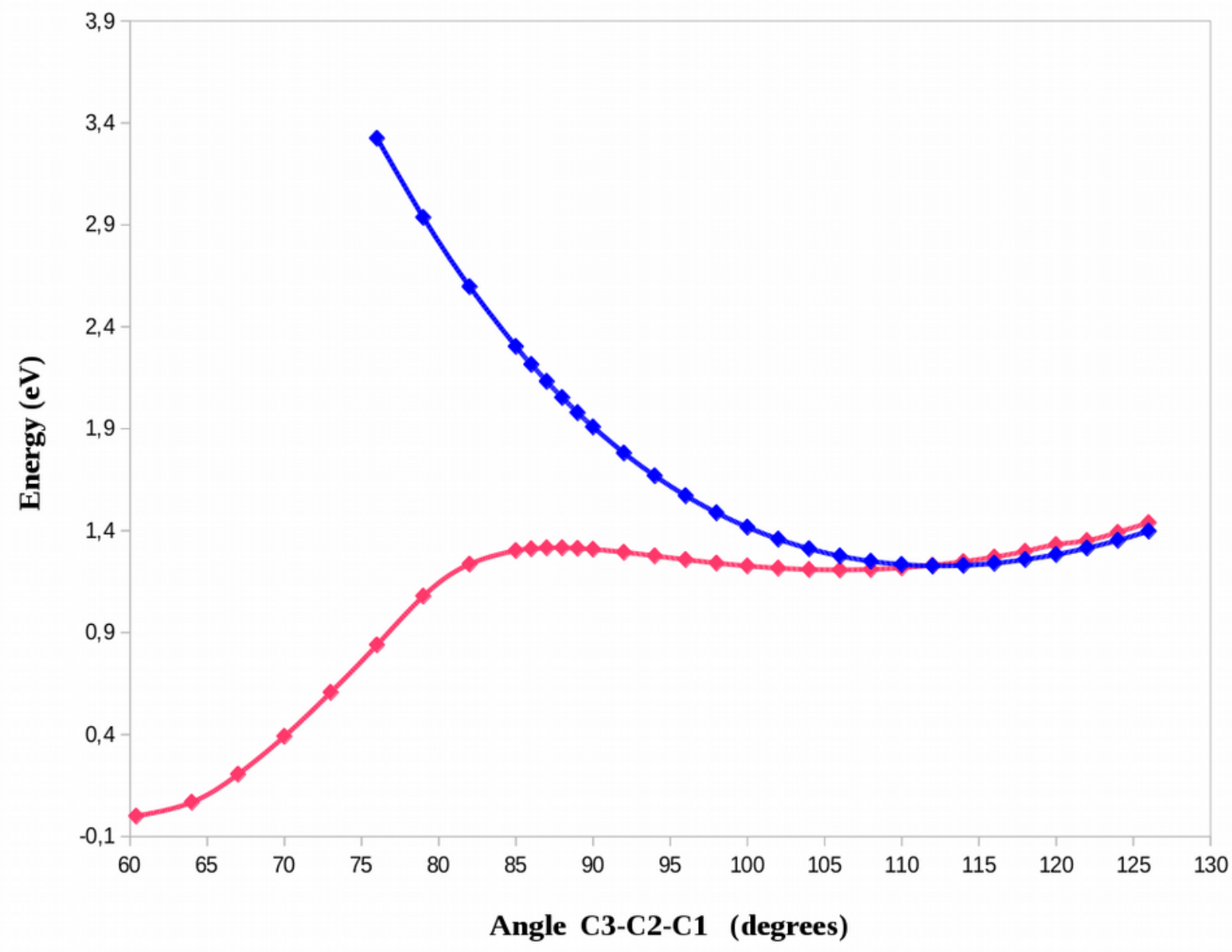

Figure 7 
(a)

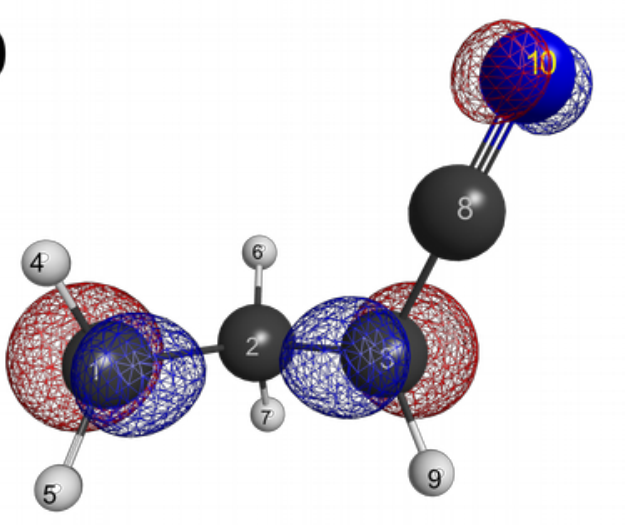

N.0.18

(Homo)

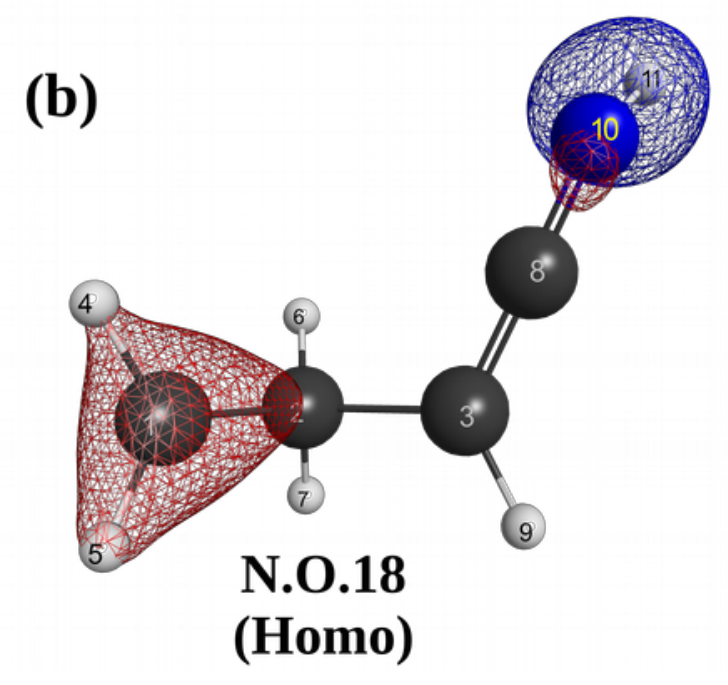

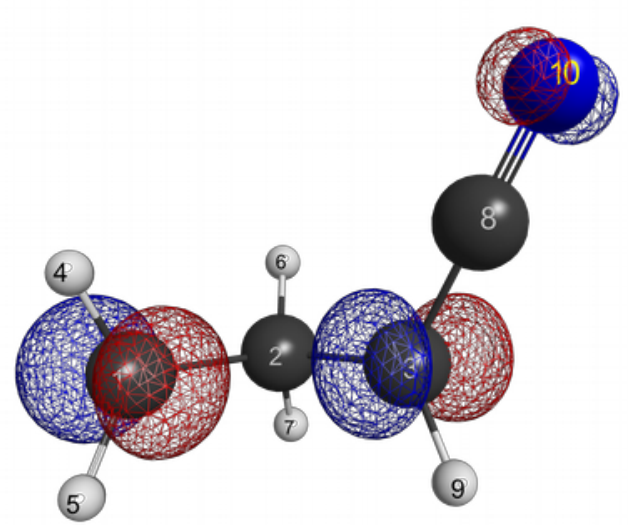

N.O.19

(Lumo)

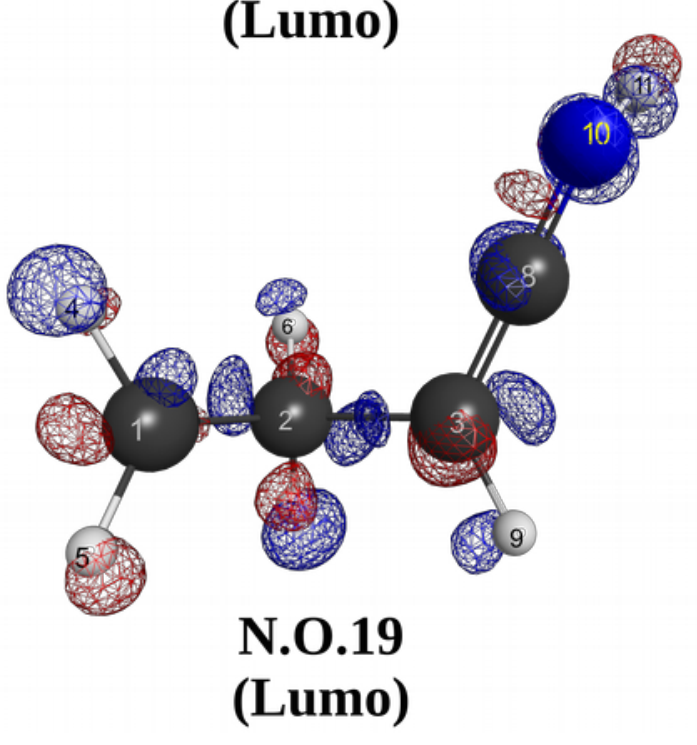

Figure 8 

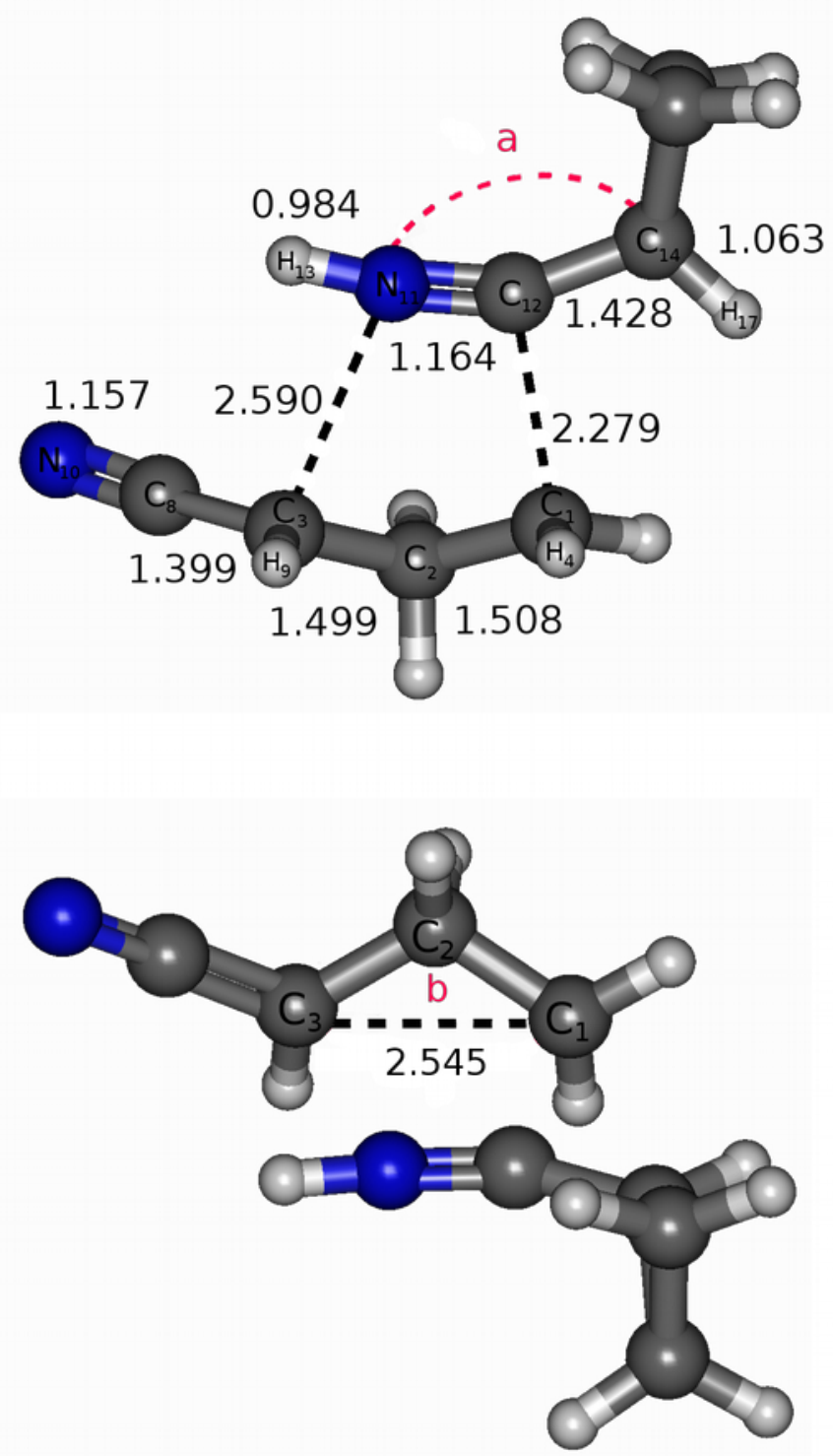

Figure 9 

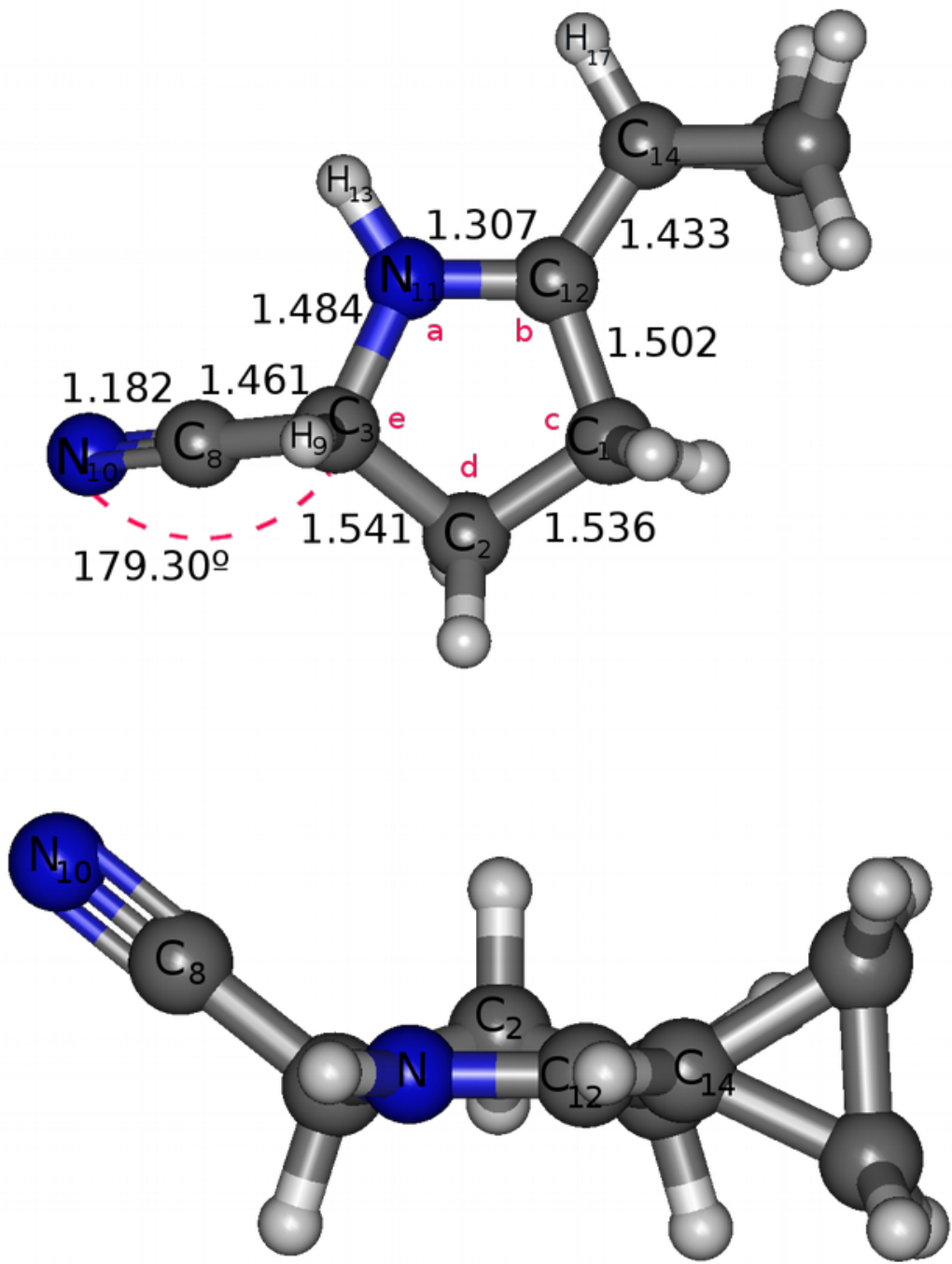

Figure 10 


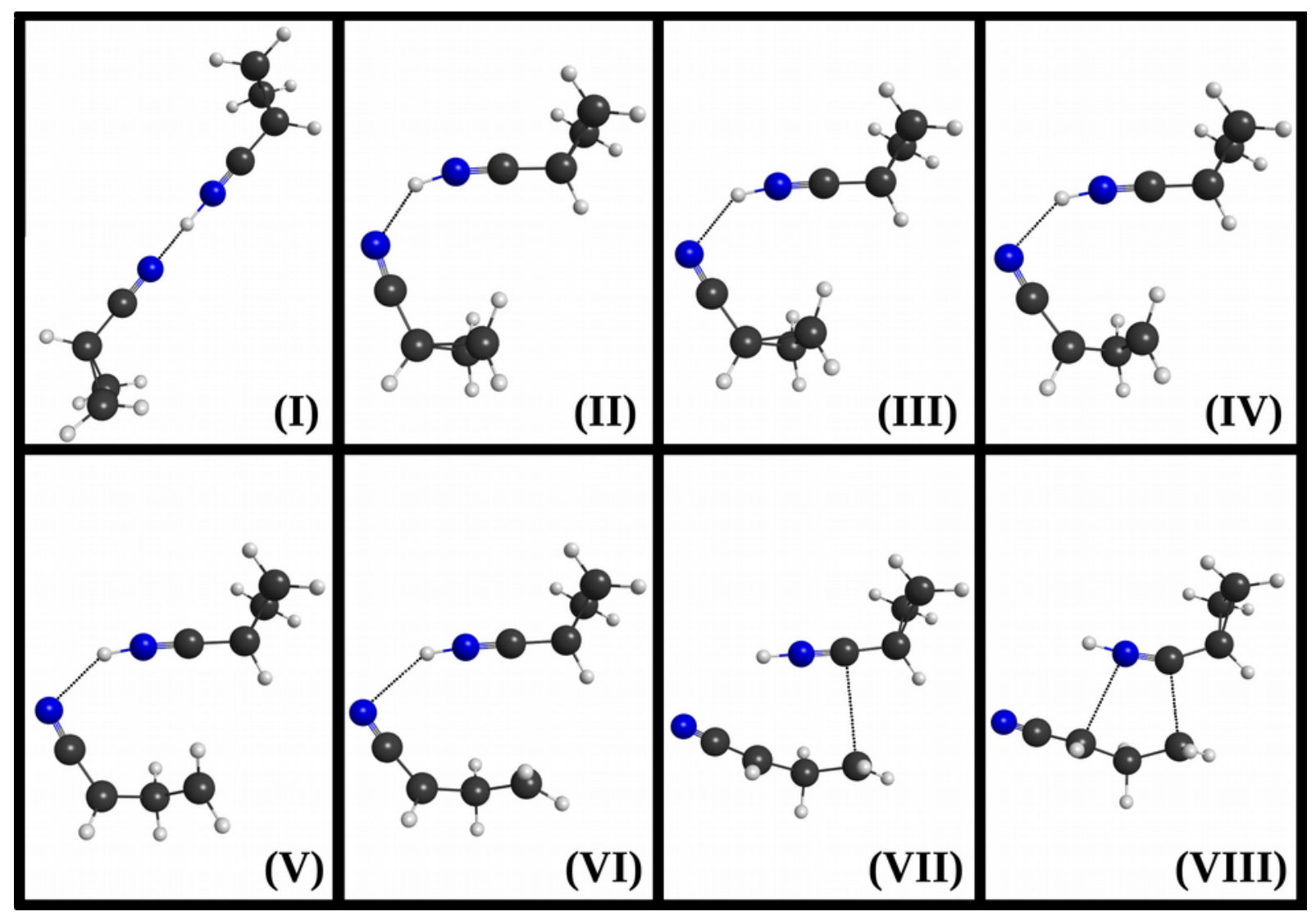

Figure 11 


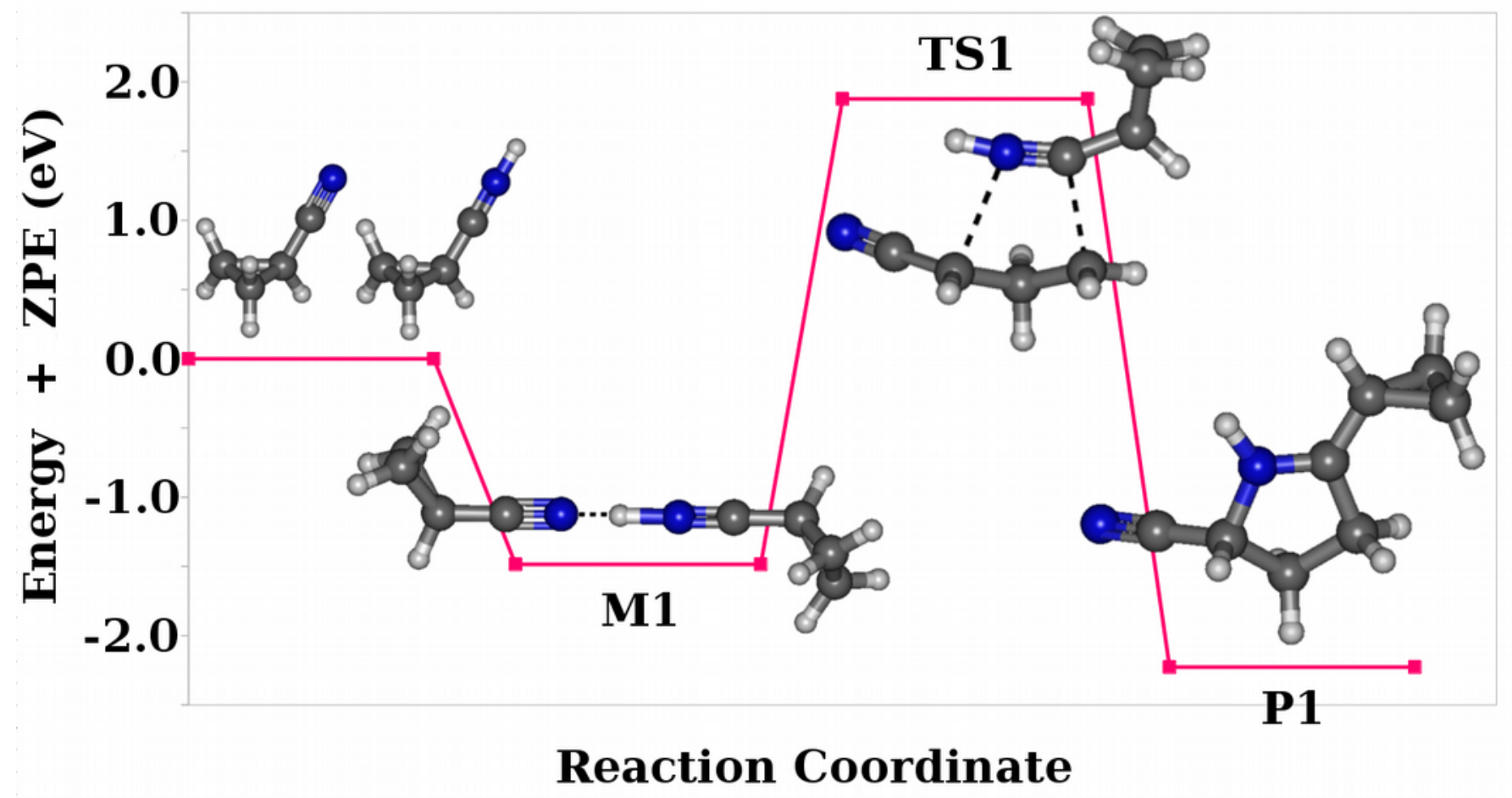

Figure 12 
TABLES

\begin{tabular}{|c|c|c|c|c|c|}
\hline & $\mathbf{C}_{\mathbf{4}} \mathbf{H}_{5} \mathbf{N}$ & $\mathbf{C}_{\mathbf{4}} \mathbf{H}_{5} \mathbf{N H}^{+}$ & & $\mathbf{C}_{\mathbf{4}} \mathbf{H}_{5} \mathbf{N}$ & $\mathbf{C}_{\mathbf{4}} \mathbf{H}_{5} \mathbf{N H}^{+}$ \\
\hline Angle & $M P 2$ & $M P 2$ & & $M P 2$ & $M P 2$ \\
\hline a & 60.41 & 61.26 & Energy & -209.50089 & -209.12868 \\
\hline b & 60.42 & 61.25 & ZPE & 0.08241 & 0.09798 \\
\hline c & 59.17 & 57.49 & Total E & -209.41848 & -209.03070 \\
\hline
\end{tabular}

Table 1: Values of angles a, b and c of cyclopropyl cyanide neutral and protonated (MP2, 6$31 \mathrm{~g}(\mathrm{~d}, \mathrm{p})$ ) geometries in Figure 3. Their electronic, ZPE, and total energies are given in hartrees.

\begin{tabular}{|c|c|c|c|c|c|}
\hline \multicolumn{7}{|c|}{$\left(\mathbf{C}_{\mathbf{4}} \mathbf{H}_{\mathbf{5}} \mathbf{N}\right)_{\mathbf{2}} \mathbf{H}^{+}$Adduct(1) } \\
\hline Angle & $\begin{array}{c}\text { Value } \\
\text { (degrees) }\end{array}$ & Angle & $\begin{array}{c}\text { Value } \\
\text { (degrees) }\end{array}$ & Angle & $\begin{array}{c}\text { Value } \\
\text { (degrees) }\end{array}$ \\
\hline C3-C2-C1 & 60.84 & $\mathbf{C 1 4 - C 1 5 - C 1 6}$ & 60.84 & $\mathbf{C 1 4 - C 1 2 - N 1 1}$ & 179.20 \\
\hline C3-C1-C2 & 60.84 & $\mathbf{C 1 4 - C 1 6 - C 1 5 ~}$ & 60.84 & N11-H13-N10 & 179.79 \\
\hline C1-C3-C2 & 58.33 & C15-C14-C16 & 58.33 & N10-C8-C3 & 179.23 \\
\hline
\end{tabular}

Table 2: Detailed angle values for the optimized equilibrium geometry of $\left[\mathrm{C}_{8} \mathrm{H}_{10} \mathrm{~N}_{2} \mathrm{H}\right]^{+}$adduct, ion-molecule adduct formed by interaction between cyclopropyl cyanide neutral and protonated, whose structure is shown at Figure 4. The calculations have been done with MP2 method and 6-31g(d,p) Pople's basis.

\begin{tabular}{|l|c|c|c|c|c|}
\hline & $\mathbf{C}_{\mathbf{4}} \mathbf{H}_{5} \mathbf{N}+\mathbf{C}_{\mathbf{4}} \mathbf{H}_{\mathbf{5}} \mathbf{N H}^{+}$ & Adduct(1) & Adduct(2) & Adduct(3) & Adduct(4) \\
\hline Energy & 0 & $-1,43142$ & $-0,73193$ & $-0,77629$ & $-0,70067$ \\
\hline ZPE & 0 & $-0,05371$ & 0,02604 & 0,03061 & 0,02161 \\
\hline Tot E & 0 & $-1,48513$ & $-0,70589$ & $-0,74568$ & $-0,67906$ \\
\hline
\end{tabular}

Table 3: Electronic energies, Zero Point Energies and Total Energies, in eV, of ion-molecule Adducts (1), (2), (3) and (4) related to reactants energies. See structures at Figures 4 and 5.

\begin{tabular}{|c|c|c|}
\hline Natural Orbital & $\begin{array}{c}\text { Open } \mathbf{C}_{\mathbf{4}} \mathbf{H}_{\mathbf{5}} \mathbf{N} \\
\text { SINGLET }\end{array}$ & Open $\mathbf{C}_{\mathbf{4}} \mathbf{H}_{\mathbf{5}} \mathbf{N H}^{+}$SINGLET \\
\hline $\mathbf{1 7}$ & 1.9480 & 2.000 \\
\hline $\mathbf{1 8}$ & 1.2561 & 2.000 \\
\hline $\mathbf{1 9}$ & 0.7439 & 0.000 \\
\hline $\mathbf{2 0}$ & 0.0520 & 0.000 \\
\hline
\end{tabular}

Table 4: NOS Occupation numbers of open $\mathrm{C}_{4} \mathrm{H}_{5} \mathrm{~N}$ and open $\mathrm{C}_{4} \mathrm{H}_{5} \mathrm{NH}^{+}$in their singlet ground state. 


\begin{tabular}{|c|c|c|c|}
\hline Angle & P1 & Dihedral Angle & P1 \\
\hline a & 114.63 & [C3-N11-C12-C1] & -0.32 \\
\hline b & 109.14 & [C2-C1-C12-N11] & 17.53 \\
\hline c & 103.44 & [C3-N11-C12-C14] & -178.36 \\
\hline d & 103.67 & [H13-N11-C12-C14] & $-1,15$ \\
\hline e & 101.28 & [H13-N11-C12-C1] & 176.85 \\
\hline
\end{tabular}

Table 5: Values of angles and dihedral angles of product P1, in degrees.

\begin{tabular}{|l|c|c|c|c|}
\hline \multicolumn{5}{|c|}{ Energy (hartrees) } \\
\hline & Reactants & Adduct(1) & TS1 & P1 \\
\hline Energy & -419.32043 & -419.37304 & -419.24631 & -419.41069 \\
\hline ZPE & 0.17558 & 0.17361 & 0.17045 & 0.18399 \\
\hline Total E & -419.14485 & -419.19943 & -419.07586 & -419.22670 \\
\hline Total E (eV) & 0.00000 & -1.48516 & 1.87727 & -2.22731 \\
\hline
\end{tabular}

Table 6: Energy, ZPE, and total Energies in hartrees, of the stationary points in

Reaction 1. Total Energy, in eV, is referred to reactants. 